\title{
THE
}

\section{Momentum Flux Budget across the Air-Sea Interface under Uniform and Tropical Cyclone Winds}

\author{
Yalin Fan \\ Isaac Ginis \\ University of Rhode Island, iginis@uri.edu \\ Tetsu Hara \\ University of Rhode Island, thara@uri.edu
}

Follow this and additional works at: https://digitalcommons.uri.edu/gsofacpubs

\section{Citation/Publisher Attribution}

Fan, Y., Ginis, I., \& Hara, T. (2010). Momentum Flux Budget across the Air-Sea Interface under Uniform and Tropical Cyclone Winds. J. Phys. Oceanogr., 40, 2221-2242. doi: 10.1175/2010JP04299.1

Available at: http://dx.doi.org/10.1175/2010JP04299.1

This Article is brought to you for free and open access by the Graduate School of Oceanography at DigitalCommons@URI. It has been accepted for inclusion in Graduate School of Oceanography Faculty Publications by an authorized administrator of DigitalCommons@URI. For more information, please contact digitalcommons-group@uri.edu. 


\title{
Momentum Flux Budget across the Air-Sea Interface under Uniform and Tropical Cyclone Winds
}

\author{
YALIN FAN \\ Atmospheric and Oceanic Sciences Program, Princeton University, and NOAA Geophysical Fluid Dynamics Laboratory, Princeton, New Jersey
}

ISAAC GINIS AND TETSU HARA

Graduate School of Oceanography, University of Rhode Island, Narragansett, Rhode Island

(Manuscript received 16 June 2009, in final form 19 April 2010)

\begin{abstract}
In coupled ocean-atmosphere models, it is usually assumed that the momentum flux into ocean currents is equal to the flux from air (wind stress). However, when the surface wave field grows (decays) in space or time, it gains (loses) momentum and reduces (increases) the momentum flux into subsurface currents compared to the flux from the wind. In particular, under tropical cyclone (TC) conditions the surface wave field is complex and fast varying in space and time and may significantly affect the momentum flux from wind into ocean. In this paper, numerical experiments are performed to investigate the momentum flux budget across the air-sea interface under both uniform and idealized TC winds. The wave fields are simulated using the WAVEWATCH III model. The difference between the momentum flux from wind and the flux into currents is estimated using an air-sea momentum flux budget model. In many of the experiments, the momentum flux into currents is significantly reduced relative to the flux from the wind. The percentage of this reduction depends on the choice of the drag coefficient parameterization and can be as large as $25 \%$. For the TC cases, the reduction is mainly in the right-rear quadrant of the hurricane, and the percentage of the flux reduction is insensitive to the changes of the storm size and the asymmetry in the wind field but varies with the TC translation speed and the storm intensity. The results of this study suggest that it is important to explicitly resolve the effect of surface waves for accurate estimations of the momentum flux into currents under TCs.
\end{abstract}

\section{Introduction}

The passage of a tropical cyclone (TC) over a warm ocean represents one of the most extreme cases of airsea interaction. One apparent effect of the TC passage is the marked cooling of the sea surface temperature (SST) of $1^{\circ}-5^{\circ} \mathrm{C}$, which occurs to the right of the storm track. The SST cooling is mainly due to the vertical turbulent mixing induced by the strong momentum flux into ocean currents and the accompanying entrainment of cooler thermocline water into the upper mixed layer. The TCocean interaction can be described as a weather system with positive and negative feedbacks (Ginis 2002). The primary energy source driving TCs is the evaporation of warm water from the ocean surface and subsequent

Corresponding author address: Yalin Fan, Atmospheric and Oceanic Sciences Program, Princeton University, 300 Forrestal Road, Princeton, NJ 08540-6654.

E-mail: yalinfan@princeton.edu latent heat release due to condensation during cloud formation. As a TC intensifies, increasing wind speed enhances the evaporation rate, thereby increasing the latent heat energy available for further intensification. However, as the TC continues to intensify, the increasing wind stress on the ocean's surface generates stronger turbulent mixing in the upper oceanic mixed layer. Increased mixing deepens the mixed layer and reduces the SST, hence causing a reduction of sea surface heat and moisture flux. This reduction may in turn decrease the intensity of the TC. Accurate predictions of sea surface and subsurface structures are essential for improving numerical TC intensity forecasting (Ginis et al. 1989; Khain and Ginis 1991; Bender and Ginis 2000). In modeling the ocean response to TCs, the momentum flux into currents $\boldsymbol{\tau}_{c}$ is the most critical parameter. Research and operational coupled atmosphere-ocean models usually assume that $\tau_{c}$ is identical to the momentum flux from air (wind stress) $\boldsymbol{\tau}_{\text {air }}$; that is, no net momentum is gained (or lost) by surface waves. This assumption, however, is invalid when 
the surface wave field is growing or decaying. The main objective of this paper is to investigate the effect of surface gravity waves on the momentum transfer budget across the air-sea interface under medium to high wind conditions. In particular, we focus on the difference between the momentum fluxes from wind and those into currents, $\tau_{\text {diff }}=\tau_{\text {air }}-\tau_{c}$, by explicitly calculating the momentum gained (or lost) due to the spatial and time variation in the surface waves and the ratio between $\left|\boldsymbol{\tau}_{c}\right|$ and $\left|\boldsymbol{\tau}_{\text {air }}\right|$. We examine spatially uniform wind forcing under duration-dependent (time over which waves are exposed to a steady and horizontally uniform wind) and fetch-dependent (distance over which waves travel under a steady and horizontally uniform wind) conditions, as well as more complex TC wind conditions.

Wave field simulations and estimations of the momentum flux budget through the air-sea interface are dependent on the parameterization of wind stress (or drag coefficient) over the sea surface. Although the wind stress has been studied for more than 50 years, current parameterizations still have significant limitations, especially in high wind conditions due to the lack of observations. Not only does the magnitude of drag coefficient $C_{d}$ vary among different studies, but the wave age (defined as $c_{p} / u_{*}$, where $u_{*}$ is the friction velocity and $c_{p}$ is the phase speed at the spectral peak frequency) dependence of $C_{d}$ is also an open question. The uncertainty of the drag coefficient affects our study in two ways. First, the source term (wind input) in the wave model depends on the drag coefficient; hence, it affects the wave field simulation. As will be shown in section 2 , the difference between the momentum flux from air and the flux into currents $\tau_{\text {diff }}$ is determined solely by the wave field. Second, to estimate the ratio between $\left|\boldsymbol{\tau}_{\text {diff }}\right|$ and $\left|\boldsymbol{\tau}_{\text {air }}\right|$ or between $\left|\boldsymbol{\tau}_{c}\right|$ and $\left|\boldsymbol{\tau}_{\text {air }}\right|$, one needs to know the wind stress $\tau_{\text {air }}$, which naturally depends on the drag coefficient parameterization.

In this study we employ the WAVEWATCH III (WWIII) wave model, developed at the NOAA National Centers for Environmental Prediction (NCEP) (Tolman 1998). WWIII has been validated against observations over both global- and regional-scale wave forecasts (Tolman 1998, 2002b; Tolman et al. 2002) and is used as the operational wave model at NCEP. Although WWIII shows a fairly good wave forecasting skill in hurricanes (Moon et al. 2003), it tends to overestimate wave heights under very high wind conditions in extreme TCs (Chao et al. 2005; Tolman and Alves 2005; Tolman et al. 2005). Moon et al. (2004a,b) modified the drag coefficient parameterization in the WWIII wind input term by replacing it with a coupled wind-wave (CWW) model. In this model, the complete wave spectrum $\psi(\omega, \theta)$ is constructed by merging the WWIII spectrum $\psi_{\text {peak }}(\omega, \theta)$ in the vicinity of the spectral peak with the spectral tail parameterization $\psi_{\text {tail }}(\omega, \theta)$ based on the equilibrium spectrum model of Hara and Belcher (2002). Once the complete wave spectrum is constructed, we can explicitly resolve the wave-induced stress based on the conservation of energy and momentum across the wave boundary layer (Hara and Belcher 2004). The CWW model produces much lower drag than the one used in the operational WWIII under very high winds (Fig. 6 in Moon et al. 2004b). Moon et al. (2008) demonstrated that the resulting wave predictions with WWIII are more consistent with observations under category 5 Hurricane Katrina (2005). Fan et al. (2009b) have further investigated the performance of WWIII with the modified momentum flux parameterization in Hurricane Ivan (2004), which reached category 5 over the Caribbean Sea and the Gulf of Mexico. By comparing the model results with the surface wave spectra measurements from the National Aeronautics and Space Administration airborne scanning radar altimeter in the vicinity of the storm center, National Data Buoy Center (NDBC) wave height time series, and satellite altimeter measurements, they confirmed that WWIII with the CWW model improves predictions of the wave field under a strong hurricane.

Based on the results of Moon et al. (2008) and Fan et al. (2009b), we assume that WWIII can simulate surface wave spectra that are accurate enough for the purpose of calculation of the differences between the momentum fluxes from wind and those into subsurface currents, $\boldsymbol{\tau}_{\text {diff }}$, provided it is forced with the momentum flux parameterization based on the CWW model. As we will discuss in section 2 , the calculation of the differences between the momentum fluxes from wind and those into subsurface currents, $\boldsymbol{\tau}_{\text {diff }}$ requires the knowledge of the directional wave spectrum $\psi(\omega, \theta)$ only. We will not investigate the sensitivity of the wave simulations to different drag coefficient parameterization in this study. However, in our analysis of the ratio between $\left|\boldsymbol{\tau}_{c}\right|$ and $\left|\boldsymbol{\tau}_{\text {air }}\right|$ in different experiments discussed below, we will explore the uncertainties in $\tau_{\text {air }}$ caused by the different drag parameterizations.

The outline of this paper is as follows: the relation between the fluxes from wind, $\tau_{\text {air }}$, and fluxes to currents, $\tau_{c}$, are formulated in section 2; a brief outline of the experimental design is introduced in section 3 ; the wave parameters produced by the model in the steady uniform wind and TC experiments are discussed in section 4; the net momentum gained/lost by growing and complex seas are presented in section 5; and the reduction of momentum flux into currents relative to wind stress is analyzed in section 6. A summary of the major results of this study and concluding remarks are presented in section 7 . 


\section{Air-sea momentum flux budget}

To understand how a growing/decaying surface wave field affects the air-sea momentum flux budget, let us first consider a wave field with a single wave component propagating in the $x$ direction. When the effect of surface currents on waves is not considered (such as in this study), the wave action equation is described as

$$
\frac{D N}{D t}=\frac{\partial N}{\partial t}+\frac{\partial\left(N C_{g}\right)}{\partial x}=S_{\text {air }}-S_{c}
$$

where $t$ is time, $N=\psi / \omega$ is the wave action, $\psi(\omega, \theta)$ is the directional frequency wave spectrum, $\omega$ is the angular frequency, $\theta$ is the wave propagation direction (here $\theta=0), C_{g}$ is the group velocity, $S_{\text {air }}$ is the wave action input from wind, and $S_{c}$ is the wave action dissipation (output into currents). If Eq. (1) is multiplied by $\rho_{w} \omega^{2}$, where $\rho_{w}$ is water density, we obtain the wave momentum equation,

$$
\frac{D M}{D t}=\frac{\partial M}{\partial t}+\frac{\partial\left(M C_{g}\right)}{\partial x}=F_{\text {air }}-F_{c},
$$

where $M=\rho_{w} \omega \psi$ is the wave momentum, $F_{\text {air }}$ is the momentum flux from wind to waves, and $F_{c}$ is the momentum flux from waves to currents. This equation states that, as the wave field propagates at its group speed, the wave momentum increases (decreases) if the momentum flux from wind to waves is more (less) than the momentum flux from waves to currents. Notice that in an Eulerian framework the change of the wave momentum (as the wave field propagates) consists of the time derivative of the wave momentum $M$ and the advection term (spatial derivative of the horizontal momentum flux $M C_{g}$ ). The sum of these two terms is equal to the difference between the momentum flux from wind to waves $F_{\text {air }}$, and the momentum flux from waves to currents $F_{c}$, as shown in Fig. 1.

When the wave field contains more than one wave component (two dimensional), the evolution of the wave momentum of each wave component is affected not only by the wind input and dissipation but also by the nonlinear wave interaction $F_{\mathrm{NL}}$ that exchanges momentum among different wave components. The momentum equation (in two dimensions, $x$ and $y$ ) now becomes

$$
\begin{aligned}
\frac{D M_{x}}{D t} & =\frac{\partial M_{x}}{\partial t}+\left[\frac{\partial\left(M_{x} C_{g x}\right)}{\partial x}+\frac{\partial\left(M_{x} C_{g y}\right)}{\partial y}\right] \\
& =F_{\text {air } x}-F_{c x}+F_{\mathrm{NL} x}
\end{aligned}
$$

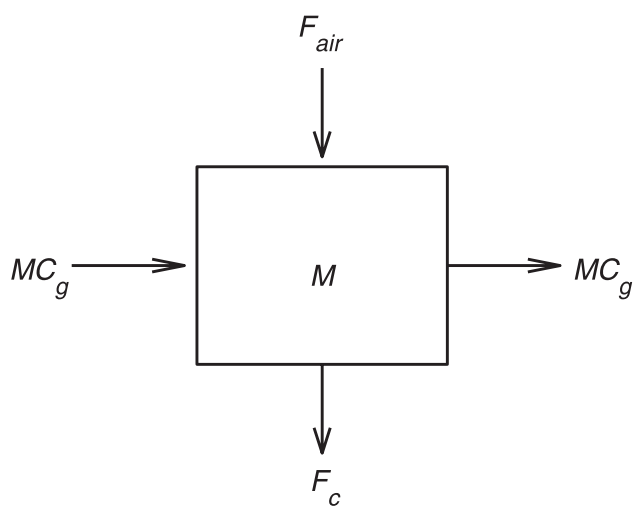

FIG. 1. Air-sea momentum flux diagram expressed in an Eulerian framework with a single wave component.

and

$$
\begin{aligned}
\frac{D M_{y}}{D t} & =\frac{\partial M_{y}}{\partial t}+\left[\frac{\partial\left(M_{y} C_{g x}\right)}{\partial x}+\frac{\partial\left(M_{y} C_{g y}\right)}{\partial y}\right] \\
& =F_{\text {air } y}-F_{c y}+F_{\mathrm{NL} y},
\end{aligned}
$$

where $M_{x}=M \cos \theta=\rho_{w} \omega \psi \cos \theta$ and $M_{y}=M \sin \theta=$ $\rho_{w} \omega \psi \sin \theta$ are the $x$ and $y$ components of the wave momentum, $M_{i} C_{g j}$ is the horizontal flux in the $j$ direction of the $i$ component of the wave momentum, and the subscripts $x$ and $y$ in the forcing terms also denote the $x$ and $y$ components. [Note: if we multiply (3) by $\cos \theta / \rho_{w} \omega^{2}$, multiply (4) by $\sin \theta / \rho_{w} \omega^{2}$, and add the two, we recover the familiar wave action equation with three forcing terms.] If these momentum equations are integrated over all frequencies and directions, the nonlinear interaction terms cancel out since the nonlinear wave interaction conserves the total momentum in the wave field. Therefore,

$$
\frac{\partial M T_{x}}{\partial t}+\left[\frac{\partial\left(M F_{x x}\right)}{\partial x}+\frac{\partial\left(M F_{x y}\right)}{\partial y}\right]=\tau_{\text {air } x}^{w}-\tau_{c x}^{w}
$$

and

$$
\frac{\partial M T_{y}}{\partial t}+\left[\frac{\partial\left(M F_{y x}\right)}{\partial x}+\frac{\partial\left(M F_{y y}\right)}{\partial y}\right]=\tau_{\text {air } y}^{w}-\tau_{c y}^{w},
$$

where

$M T_{x}=\iint M_{x} d \theta d \omega=\iint \rho_{w} \omega \psi(\omega, \theta) \cos \theta d \theta d \omega$

and

$M T_{y}=\iint M_{y} d \theta d \omega=\iint \rho_{w} \omega \psi(\omega, \theta) \sin \theta d \theta d \omega$ 
are the total momentum in the $x$ and $y$ directions contained in the wave field;

$$
M F_{x x}=\iint M_{x} C_{g x} d \theta d \omega=\iint \rho_{w} \omega C_{g} \psi(\omega, \theta) \cos ^{2} \theta d \theta d \omega,
$$

$$
\begin{aligned}
M F_{x y} & =\iint M_{x} C_{g y} d \theta d \omega \\
& =\iint \rho_{w} \omega C_{g} \psi(\omega, \theta) \cos \theta \sin \theta d \theta d \omega \\
M F_{y y} & =\iint M_{y} C_{g y} d \theta d \omega=\iint \rho_{w} \omega C_{g} \psi(\omega, \theta) \sin ^{2} \theta d \theta d \omega
\end{aligned}
$$

and

$$
\begin{aligned}
M F_{y x} & =\iint M_{y} C_{g x} d \theta d \omega \\
& =\iint \rho_{w} \omega C_{g} \psi(\omega, \theta) \sin \theta \cos \theta d \theta d \omega
\end{aligned}
$$

are the integrated horizontal momentum flux terms.

From the atmosphere,

$$
\tau_{\text {air } x}^{w}=\iint F_{\text {air } x} d \theta d \omega ; \quad \tau_{\text {air } y}^{w}=\iint F_{\text {airy }} d \theta d \omega
$$

are the $x$ and $y$ components of the total (integrated) momentum flux from wind to waves $\boldsymbol{\tau}_{\text {air }}^{w}$, and in the ocean,

$$
\tau_{c x}^{w}=\iint F_{c x} d \theta d \omega ; \quad \tau_{c y}^{w}=\iint F_{c y} d \theta d \omega
$$

are the $x$ and $y$ components of the total (integrated) momentum flux from waves to currents. The total momentum flux from wind (wind stress) $\tau_{\text {air }}$ consists of the total flux to waves $\tau_{\text {air }}^{w}$ and the direct flux to currents (surface viscous stress), $\tau_{\text {visc }}$; that is,

$$
\tau_{\text {air }}=\tau_{\text {air }}^{w}+\tau_{\text {visc }} .
$$

The total momentum flux into currents $\boldsymbol{\tau}_{c}$ consists of the total flux from waves $\boldsymbol{\tau}_{c}^{w}$ and the direct flux from wind (surface viscous stress) $\tau_{\text {visc }}$; that is,

$$
\tau_{c}=\tau_{c}^{w}+\tau_{\mathrm{visc}}
$$

Therefore, the difference between the total momentum flux from wind (wind stress) $\tau_{\text {air }}$ and the total momentum flux to currents $\tau_{c}$ is expressed as

$$
\tau_{\text {diff }}=\tau_{\text {air }}-\tau_{c}=\tau_{\text {air }}^{w}-\tau_{c}^{w} ;
$$

that is, it is equal to the difference between the total momentum flux from wind to waves $\tau_{\text {air }}^{w}$ and the total momentum flux from waves to currents $\tau_{c}^{w}$. In summary, if (17) is combined with (5) and (6), the difference between the momentum flux from wind and the flux into currents $\tau_{\text {diff }}$ is balanced by the two terms; that is, the time derivative of the total (integrated) wave momentum in the wave field and the spatial divergence of the total (integrated) horizontal momentum flux:

$$
\tau_{\text {diff } x}=\tau_{\text {air } x}-\tau_{c x}=\frac{\partial M T_{x}}{\partial t}+\left[\frac{\partial\left(M F_{x x}\right)}{\partial x}+\frac{\partial\left(M F_{x y}\right)}{\partial y}\right]
$$

and

$$
\tau_{\text {diffy }}=\tau_{\text {airy }}-\tau_{c y}=\frac{\partial M T_{y}}{\partial t}+\left[\frac{\partial\left(M F_{y x}\right)}{\partial x}+\frac{\partial\left(M F_{y y}\right)}{\partial y}\right] .
$$

To calculate $\boldsymbol{\tau}_{\text {diff }}$, one needs to estimate both the momentum contained in the wave field and the horizontal momentum flux due to wave propagation; hence, the directional surface wave spectra must be known at all spatial locations and at all times. Although such information is not easily obtained from direct observations, it can be simulated using a numerical wave model, provided the model output is carefully validated against available observations.

In summary, the momentum flux into ocean currents is the sum of the momentum flux (by the surface viscous stress) from wind and the momentum flux from waves due to breaking. Since the surface viscous stress is not explicitly estimated in the wave model, it must be obtained by estimating the total momentum flux from wind to waves and subtracting the result from the total momentum flux from wind (i.e., wind stress). Therefore, the only practical way to estimate the momentum flux into ocean currents is to

1) estimate the difference between the momentum flux from wind to waves and the momentum flux from waves to currents due to breaking and

2) subtract the result from the total momentum flux from wind (i.e., wind stress).

As we have shown, step 1) can be achieved in two ways:

1a) estimate both the momentum flux from wind to waves and the momentum flux from waves to currents due to breaking and then calculate the difference and 
1b) estimate the net momentum gain/loss by surface waves using Eqs. (18) and (19).

We have chosen the approach 1b) instead of 1a) because neither the momentum flux from wind to waves nor the momentum flux from waves to currents due to breaking can be calculated from the standard outputs of the wave model, but approach $1 \mathrm{~b}$ ) can be easily achieved using the wave spectrum output, which is a standard output of the wave model. The consistency between the air-sea budget analysis of this study and other wave-current theories are also discussed in appendix $\mathrm{C}$.

We utilize the WWIII model (Tolman 2002a) to simulate the evolution of wave spectra under both steady uniform wind and TC wind. The ocean is assumed to be very deep: $k|D| \gg 1$, where $k$ is the wavenumber and $D$ is the water depth); therefore, surface waves are not influenced by the ocean bottom. We will focus our analysis on ocean areas away from the boundaries and, therefore, are not concerned with any boundary effects. The wave spectrum is calculated in 24 directions. In each direction, the spectrum is discretized using 40 frequencies extending from $f=0.0285$ to $1.1726 \mathrm{~Hz}$ (wavelength of 1.1-1920 m) with a logarithmic increment of $f_{n+1}=$ $1.1 f_{n}$, where $f_{n}$ is the $n$th frequency. We employ the coupled wave-wind model of Moon et al. (2004a) to calculate the source term inside the WWIII. Although $\tau_{\text {air }}$ calculated using the CWW is not necessarily consistent with recent field observations at very high winds (see section 6), we employ this parameterization for the source term simply because it (combined with the other empirical parameterizations inside the WWIII) yields the best model-data comparison in high wind and TC conditions (Moon et al. 2008; Fan et al. 2009b). We will, however, explore the uncertainty of the flux budget caused by the different drag parameterizations in section 6.

Once the wave field is simulated, the horizontal momentum contained in the wave field in the $x$ and $y$ directions $\left(M T_{x}\right.$ and $\left.M T_{y}\right)$ and the horizontal momentum fluxes $M F_{x x}, M F_{x y}, M F_{y x}$, and $M F_{y y}$ are calculated using (7)-(12). In these calculations the wave spectrum is integrated over the entire frequency range and beyond the range explicitly resolved by WWIII. Therefore, the spectral tail must be attached to the WWIII output. The results presented in this paper have been obtained using the spectral tail parameterization of the CWW model. We have also tested other parameterizations [including one case with no (zero) tail] and have found that the horizontal momentum in the wave field and horizontal momentum fluxes are not sensitive to different choices of the spectral tail (appendix B). This is expected from the following simple analysis.
It is known that the calculation of the momentum flux from wind to waves is strongly dependent on the spectral tail parameterization. If we employ the well-known wave growth rate parameterization,

$$
\beta \propto \omega\left(\frac{u_{*}}{c}\right)^{2},
$$

and assume a spectral tail proportional to $\omega^{-5}$, the momentum flux to the tail is expressed as (ignoring the directional spreading)

$\int \beta M d \omega \propto \int \omega\left(\frac{u_{*}}{c}\right)^{2} \rho_{w} \omega \psi d \omega \propto \frac{\rho_{w} u_{*}^{2}}{g^{2}} \int \omega^{-1} d \omega ;$

that is, it is roughly proportional to the integral of $\omega^{-1}$. Therefore, the contribution from the spectral tail is expected to be significant. In fact, if the integration is performed to $\omega=\infty$, the solution does not converge.

In contrast, the calculations of the wave momentum in the wave field and the horizontal momentum flux are

$$
\int M d \omega=\int \rho_{w} \omega \psi d \omega \propto \rho_{w} \int \omega^{-4} d \omega
$$

and

$$
\int M C_{g} d \omega=\int \rho_{w} \omega \psi C_{g} d \omega \propto \rho_{w} g \int \omega^{-5} d \omega,
$$

which are roughly proportional to the integral of $\omega^{-4}$ and $\omega^{-5}$. Therefore, the contribution of the spectral tail is significantly less compared to the calculation of the momentum flux from wind to waves.

The differences between the momentum fluxes from the wind and those into the subsurface currents, $\tau_{\text {diff }}$, are estimated by considering the complete momentum budget in the Eulerian framework as expressed in (18) and (19). Note that the calculation of $\boldsymbol{\tau}_{\text {diff }}$ using (7)-(12), (17), and (18) requires the knowledge of the directional wave spectrum $\psi(\omega, \theta)$ only. Therefore, the accuracy of the $\tau_{\text {diff }}$ estimation is solely dependent on the accuracy of the wave spectrum output from WWIII.

\section{Experimental design}

The air-sea flux budget is investigated in a series of numerical experiments. We consider both steady uniform wind and TC wind problems.

\section{a. Steady uniform wind experiments}

For the steady uniform wind experiments, we consider a duration-dependent problem and a fetch-dependent problem under steady uniform wind from 10 to $50 \mathrm{~m} \mathrm{~s}^{-1}$ 
with an increment of $10 \mathrm{~m} \mathrm{~s}^{-1}$. The model domains for these experiments are shown in Fig. 2. For the fetchdependent experiments, we apply a spatially uniform eastward wind over the model domain of $10^{\circ}$ in the latitude and $40^{\circ}$ in the longitude directions with $1 / 12^{\circ}$ resolution (Fig. 2a). The water depth is set to $4000 \mathrm{~m}$ for the whole domain so that the surface gravity waves have no interaction with the bottom. We analyze the wave parameters and surface wave spectrum along the middle cross section of the model domain between $0^{\circ}$ and $30^{\circ}$ longitude after $72 \mathrm{~h}$ of the model integration. By that time the wave field becomes steady along this cross section in all experiments. For the duration-dependent experiments, we apply a spatially uniform eastward wind over the model domain of $10^{\circ}$ latitude and $60^{\circ}$ longitude with $1 / 3^{\circ}$ resolution (Fig. $2 b$ ). The model is integrated for $72 \mathrm{~h}$ using a time increment of $100 \mathrm{~s}$. We analyze the mean wave parameters and surface wave spectrum at a grid point $5^{\circ}$ from the south boundary and $55^{\circ}$ from the west boundary. According to our estimation based on the model results, the wave field becomes fetch dependent after $\sim 78 \mathrm{~h}$ at this location when the wind speed is $50 \mathrm{~m} \mathrm{~s}^{-1}$ [our estimation is also consistent with Goda's (2003) formula, which gives the minimum duration as a function of 10-m wind speed and fetch]. Therefore, we will investigate the duration-dependent problem for the first $72 \mathrm{~h}$ only, which represents a pure duration-dependent problem. In all of these experiments the effect of the model boundaries is negligible, and the wave fields remain spatially homogenous during the first $72 \mathrm{~h}$ around the chosen grid point.

\section{b. TC experiments}

For the TC experiments, we use a rather simple TC wind field model, based on the analytical framework proposed by Holland (1980). The model requires the central and ambient pressure, the maximum wind speed (MWS), and the radius of maximum wind speed (RMW) as inputs and output wind speed as a function of radial distance from the center. The key TC parameters in our TC experiments are listed in Table 1. In experiments A and B, stationary axisymmetric TCs with different RMWs and MWSs are examined to study how the airsea momentum flux budget is affected by changes in the TC parameters. In experiment A, the RMW varies from 30 to $90 \mathrm{~km}$ with a fixed MWS of $45 \mathrm{~m} \mathrm{~s}^{-1}$ and, in experiment $\mathrm{B}$, the MWS varies from 35 to $55 \mathrm{~m} \mathrm{~s}^{-1}$ with a fixed RMW of $70 \mathrm{~km}$. The effect of different translation speed (TSP) is investigated in experiment $\mathrm{C}$ by moving an axisymmetric TC with a constant TSP of 5 and $10 \mathrm{~m} \mathrm{~s}^{-1}$. In experiment $\mathrm{D}$, the effect of asymmetric wind structure is investigated by adding half of the TSP

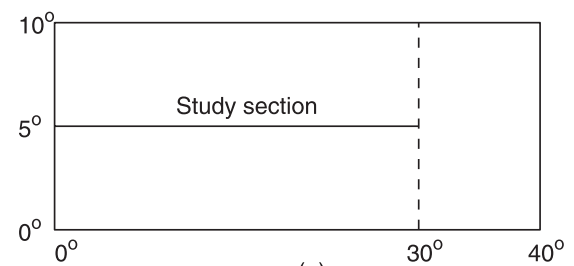

(a)

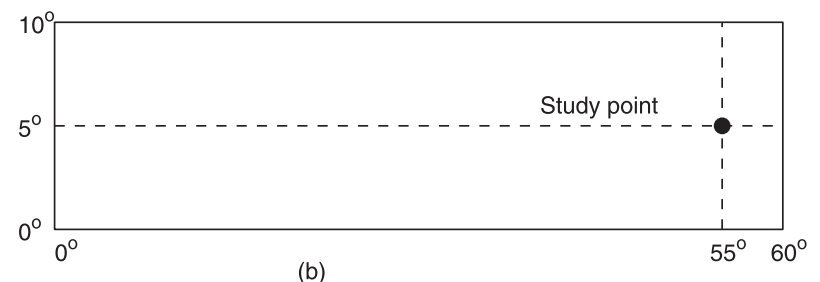

(b)

FIG. 2. Domain configurations for the (a) fetch-dependent and (b) duration-dependent experiments.

to the axisymmetric wind field. In all experiments we set the ambient pressure to $1012 \mathrm{hPa}$ and the central pressure to $968 \mathrm{hPa}$.

The model domain is set to be $10^{\circ}$ latitude and $10^{\circ}$ longitude for the stationary TC experiments and $30^{\circ}$ latitude and $18^{\circ}$ longitude for the moving TC experiments. In all experiments the grid increment is $1 / 12^{\circ}$ in both directions and the time increment is $100 \mathrm{~s}$. The water depth is set to $4000 \mathrm{~m}$ for the whole domain so that the surface gravity waves have no interaction with the bottom. All results are presented after a spinup time of $54 \mathrm{~h}$ when a quasi-steady state is achieved. In the case of a moving TC a quasi-steady state is achieved relative to the TC center.

\section{Wave parameters}

\section{a. Steady uniform wind experiments}

The time dependence of significant wave height $H_{s}$, mean wavelength $L$, and wave age $c_{p} / u_{*}$ are shown in the left panels in Fig. 3. Note that in the experiment with wind speeds of $50 \mathrm{~m} \mathrm{~s}^{-1}$ we only show the results for the first $45 \mathrm{~h}$. This is because the model becomes unstable after 45 hours of integration. The right panels in Fig. 3 show variations of $H_{s}, L$, and $c_{p} / u_{*}$ with distance after $72 \mathrm{~h}$ in the fetch-dependent experiment. Note that, for the lowest wind speed of $10 \mathrm{~m} \mathrm{~s}^{-1}$, the wave field becomes fully developed $\left(H_{s}\right.$ and $L$ become constant and $c_{p} / u_{*}$ becomes constant and above 30$)$ after about $50 \mathrm{~h}$ in the time-dependent case and at the distance of about $15^{\circ}(1620 \mathrm{~km})$ from the west boundary in the fetchdependent case. However, for higher wind speeds the wave fields do not reach the fully developed state in our calculations. They continuously grow with time/fetch and 
TABLE 1. Experimental designs of the TC experiments.

\begin{tabular}{llccr}
\hline \hline Expt & \multicolumn{1}{c}{ TC type } & TSP $\left(\mathrm{m} \mathrm{s}^{-1}\right)$ & MWS $\left(\mathrm{m} \mathrm{s}^{-1}\right)$ & RMW \\
\hline A & Axisymmetric, stationary & 0 & 45 & $30,40,50,60,70,80,90$ \\
B & Axisymmetric, stationary & 0 & $35,45,55$ & 70 \\
C & Axisymmetric, moving & 5,10 & 45 & 70 \\
D & Asymmetric, moving & 5,10 & 45 & 70 \\
\hline
\end{tabular}

the wave age is also increasing but remaining below 30 as seen in Fig. 3c. For the $50 \mathrm{~m} \mathrm{~s}^{-1}$ experiment, the wave age only reaches 15 for both time- and fetch-dependent experiments, indicating the waves remain young in these experiments. It is shown in appendix A that the wave fields simulated with WWIII appear to have the same growth relation with fetch compared with Donelan et al. (1992) but slightly slower with fetch than Hasselman et al. (1973). The normalized significant wave height in the model simulations (in both the time-dependent and fetchdependent experiments) is related to the wave age with the same power law as in the observations.

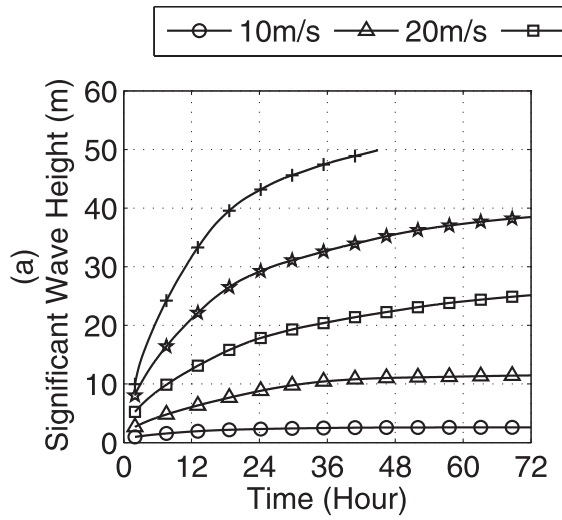

$30 \mathrm{~m} / \mathrm{s} \approx-40 \mathrm{~m} / \mathrm{s} \longleftarrow 50 \mathrm{~m} / \mathrm{s}$
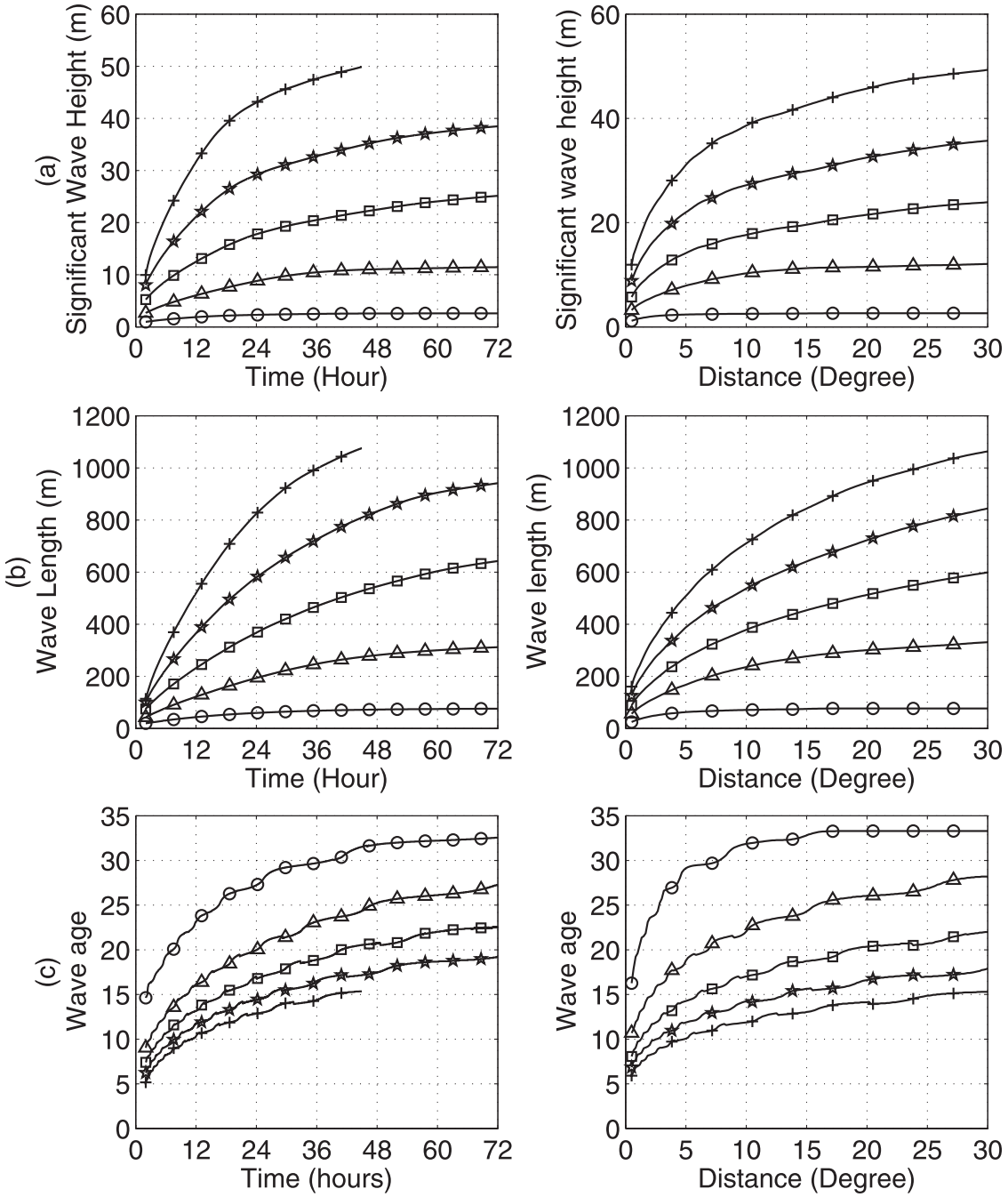

FIG. 3. Variation of (a) significant wave height $H_{s}$, (b) mean wavelength $L$, and (c) wave age $c_{p} / u_{*}$ vs (left) time and (right) distance simulated with steady homogenous winds of $10,20,30$, 40 , and $50 \mathrm{~m} \mathrm{~s}^{-1}$, as shown by different symbols in the legend. 

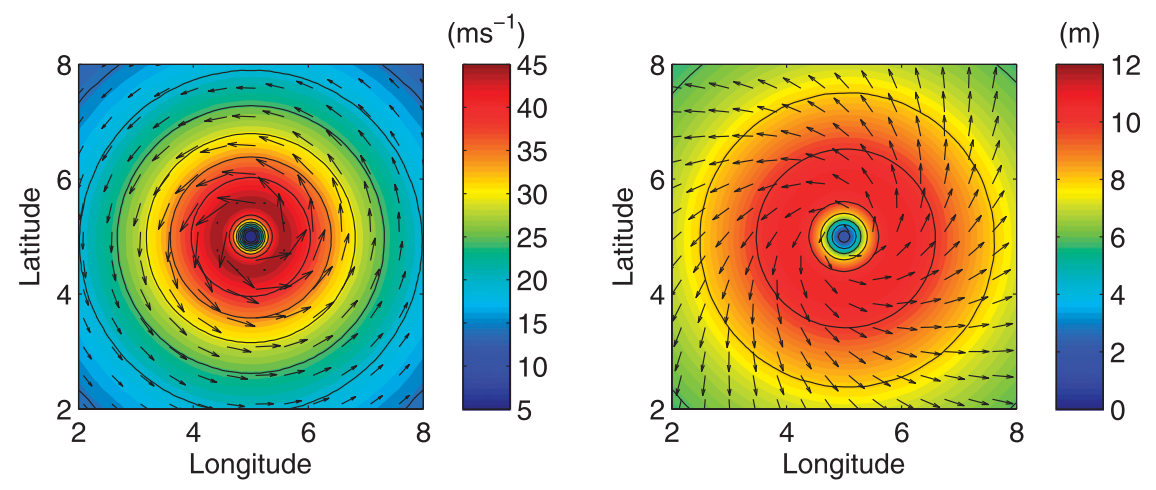

FIG. 4. (left) Wind field in expt A with RMW $=70 \mathrm{~km}$ : the arrows indicate wind speed vector, and the color scales indicate wind speed $\left(\mathrm{m} \mathrm{s}^{-1}\right)$, contours every $5 \mathrm{~m} \mathrm{~s}^{-1}$. (right) Wave field under the stationary TC: the arrows indicate dominant wave direction, and the color scales indicate significant wave height $(\mathrm{m})$, contours every $2 \mathrm{~m}$.

\section{b. TC experiments}

\section{1) StATIONARY TC}

Figure 4 shows the stationary axisymmetric TC wind field in experiment $\mathrm{A}$ with MWS $=45 \mathrm{~m} \mathrm{~s}^{-1}$ and $\mathrm{RMW}=$ $70 \mathrm{~km}$ (left panel) and the generated wave field within $3^{\circ}$ of the TC center (right panel). The wind speed increases rapidly from zero to the MWS within the radius of maximum wind speed and decreases slowly outside the RMW. In the axisymmetric wave field all waves propagate away from the TC center to the right of the wind direction. After the wave field becomes steady, it can only affect the airsea momentum flux budget through the horizontal momentum flux divergence. Because both the wind field and the wave field are axisymmetric in all stationary TC experiments, we analyze the results along one of the radii.

Figure 5 shows the wind and wave parameters in experiment A. There are no results shown close to the center because the spatial resolution of our model is not sufficient to resolve the wave field in this region. In the Holland TC wind model, the wind radial profiles relative to the normalized distance (distance from the center normalized by the RMW) are practically independent of the RMW within the RMW and only slightly different at the storm periphery (Fig. 5a). The significant wave height $H_{s}$ reaches maximum at about 1.5-2 RMW (Fig. 5b). The magnitude of the maximum $H_{s}$ increases as the RMW increases. This is because the fetch (the distance over which the spectral components in the vicinity of the spectral peak have been exposed to the wind longer as they propagate) increases as the RMW increases. The angle between the wave propagation direction and wind direction only slightly increases with the RMW at the storm periphery (Fig. 5c). The "input wave age," $g /\left(2 \pi f_{p i} u_{*}\right)$, is defined in this study as in Moon et al. (2004b). Here $f_{p i}$ is the peak frequency of the wind sea (waves directly forced by wind) and is different from the conventional peak frequency $f_{p}$, which is calculated from the onedimensional spectrum. The input wave age represents the state of growth of wind waves relative to local wind forcing. In a TC-generated complex multimodal wave field, it is essential to find the peak frequency of the wind sea to establish a reliable value of the wave age. Within the WAVEWATCH III wave model, estimation of $f_{p i}$ is made following the formulation described in Tolman and Chalikov (1996). In Fig. 5d, the input wave age reaches minimum of $\sim 6-7$ near the RMW where the youngest sea is produced and then gradually increases with distance from the storm center. This increase is more rapid in the experiments with the larger RMWs, implying that at a given normalized radius the wave age increases with an increase of the RMW.

The wind and wave parameters in experiment $\mathrm{B}$ are shown in Fig. 6. In the Holland TC wind model, the wind profile significantly varies with the MWS if the pressure difference is kept constant: as the MWS increases, the wind speed decreases more rapidly outside of the RMW (Fig. 6a). The significant wave height increases with the increase of the MWS, and its maximum is located closer to the RMW (Fig. 6b). The angle between the dominant wave direction and wind direction increases with the increase of the MWS because the wind speed decreases more rapidly outside the RMW; therefore, strong wind forcing is more localized near the RMW. The input wave age decreases with the increase of the MWS (Fig. 6d), consistent with the results of the uniform wind experiments in section 4 and other studies indicating that higher winds produce younger waves.

\section{2) Moving TC}

The distributions of significant wave height, dominant wave direction, and mean wavelength for the TSP of 5 
(a)

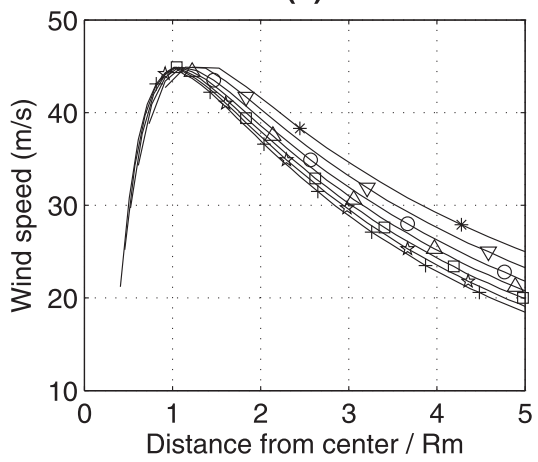

(c)

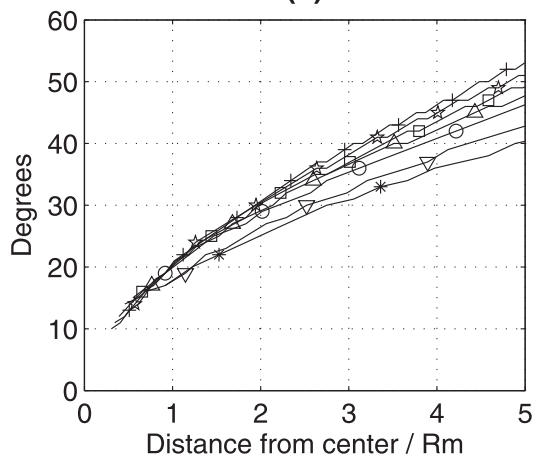

(e)

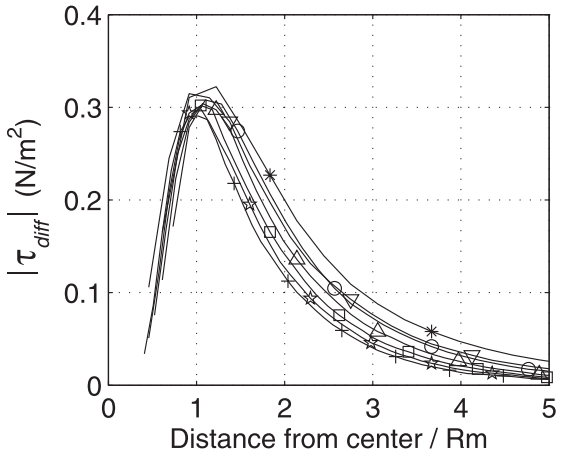

(b)

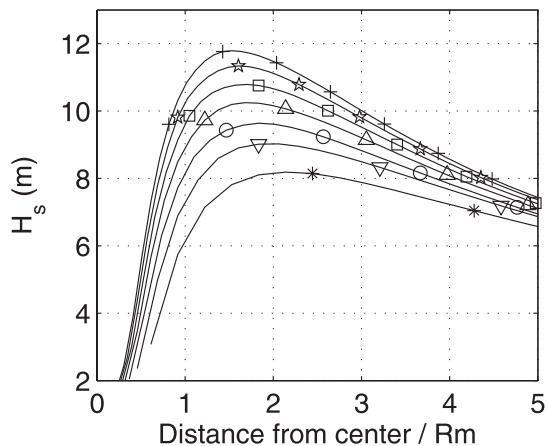

(d)

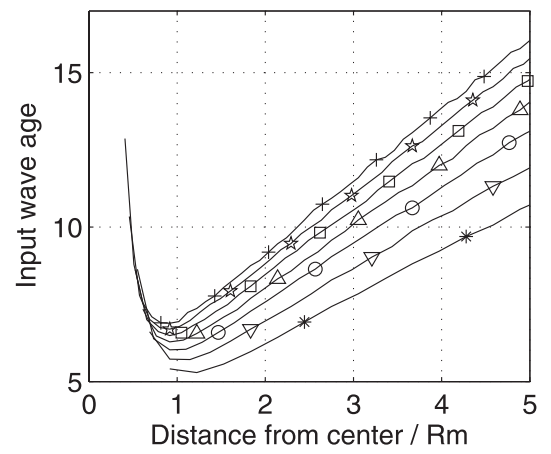

(f)

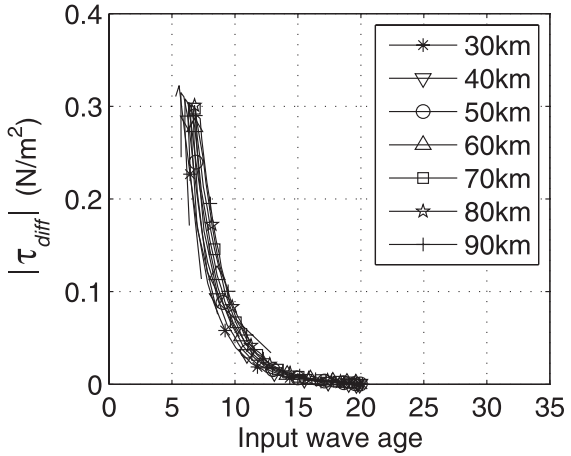

FIG. 5. Results for the stationary axisymmetric TCs in expt A with different RMWs: (a) wind profile, (b) significant wave height (m), (c) angle between wave propagation direction and wind direction, (d) input wave age, (e) net momentum flux gain/loss $\tau_{\text {diff }}$ vs normalized distance from the center, and (f) net momentum flux gain/loss $\tau_{\text {diff }}$ vs input wave age. Different symbols denote different RMWs, as shown in the legend.

and $10 \mathrm{~m} \mathrm{~s}^{-1}$ are shown in Figs. 7a and 7b. The waves in the front-right quadrant of the storm track are higher and longer due to the resonance effect caused by the movement of the TC, while those in the rear-left quadrant are lower and shorter. These wave field patterns are in a good agreement with observations and other modeling studies (Wright et al. 2001; Moon et al. 2003; Young 2006). As the TSP increases, the wave height and length differences between the front-right and rear-left quadrants increase too.

Figures $7 \mathrm{c}$ and $7 \mathrm{~d}$ show the spatial distribution of the input wave age $\left(c_{p i} / u_{*}\right)$ for TSP of 5 and $10 \mathrm{~m} \mathrm{~s}^{-1}$. As the
TSP increases, the input wave age increases to the right of the TC track. This is because, when the TSP approaches or exceeds the group velocity of the dominant waves (between 8 and $10 \mathrm{~m} \mathrm{~s}^{-1}$ ), the waves become "trapped" within the TC and thus produce the older seas.

\section{Net momentum flux gain/loss by growing and complex seas}

In this section, we present the results of the difference between the momentum flux from the wind and the flux 
(a)

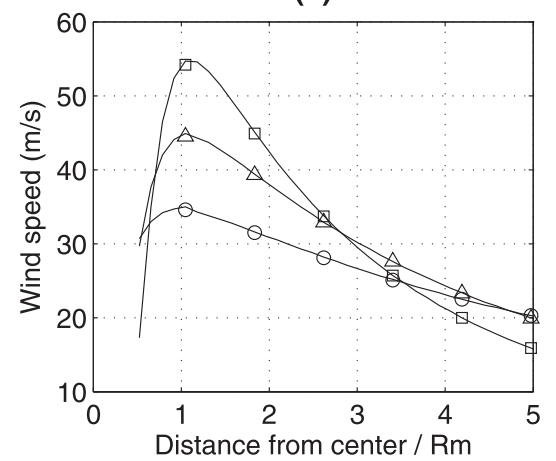

(c)

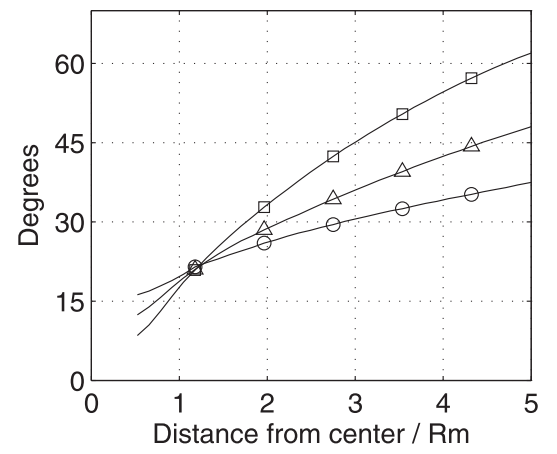

(e)

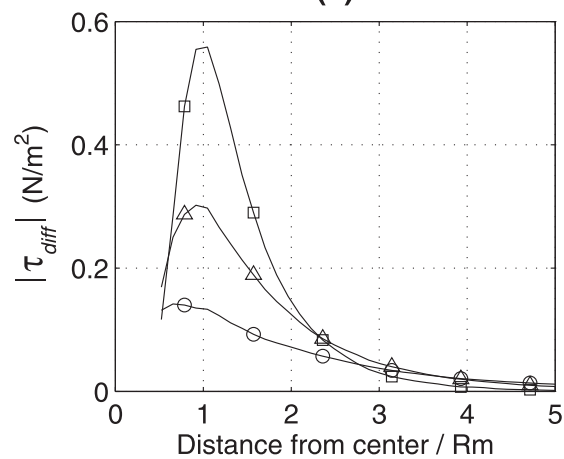

(b)

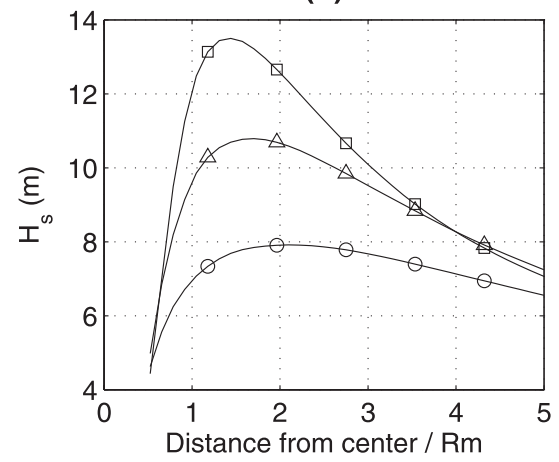

(d)

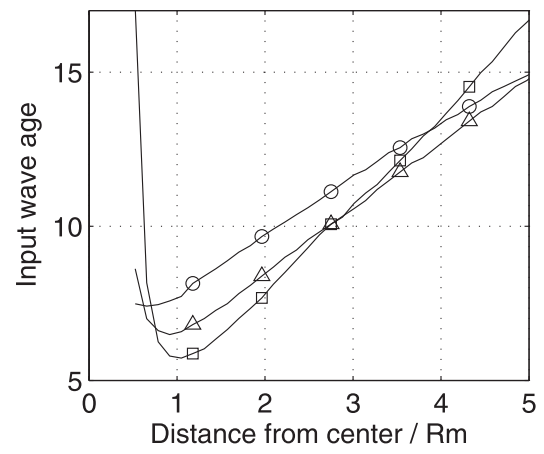

(f)

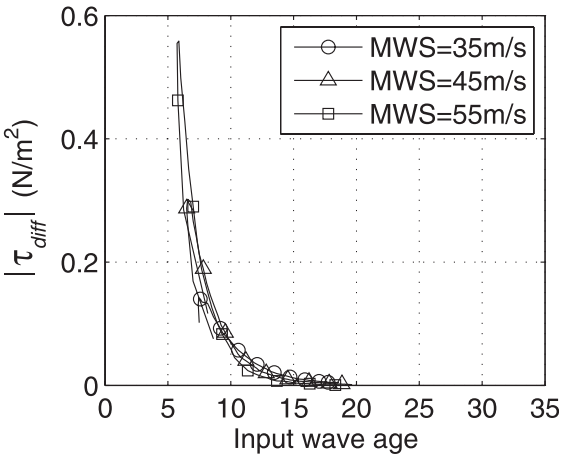

FIG. 6. As in Fig. 4, but for stationary symmetric TCs with different MWSs (expt B). Symbols denote different MWSs, as shown in the legend.

into currents: that is, the net momentum flux gain/loss by waves, $\left|\boldsymbol{\tau}_{\text {diff }}\right|$, in the steady uniform wind and TC wind experiments.

\section{a. Steady uniform wind experiments}

The $\left|\boldsymbol{\tau}_{\text {diff }}\right|$ for both duration- and fetch-dependent experiments are presented in Fig. 8. The results are shown against both dimensional time/space (left) and the wave age (right). We can see that the results against the wave age are very similar between the duration- and fetchdependent cases with $\left|\boldsymbol{\tau}_{\text {diff }}\right|$ being a little larger for the duration-dependent cases. The higher the wind speed, the more momentum the wave field gains. For the same wind the younger waves gain more momentum than the older waves. For higher wind speed $\left(U_{10} \geq 30 \mathrm{~m} \mathrm{~s}^{-1}\right)$ $\left|\boldsymbol{\tau}_{\text {diff }}\right|$ decrease rapidly with wave age before wave age 15 . At the highest wind speed of $50 \mathrm{~m} \mathrm{~s}^{-1},\left|\boldsymbol{\tau}_{\text {diff }}\right|$ is as large as $0.4-0.6 \mathrm{~N} \mathrm{~m}^{-2}$, which is a significant fraction of the total wind stress (see section 6).

\section{b. TC experiments}

\section{1) StATionary TC}

The $\left|\boldsymbol{\tau}_{\text {diff }}\right|$ profiles along the radii direction roughly follow the wind profile with the maximum at the RMW and decrease toward both the storm center and periphery (Fig. 5e). The $\left|\boldsymbol{\tau}_{\text {diff }}\right|$ profiles are practically independent of 
(a) $\mathrm{TSP}=5 \mathrm{~ms}^{-1}$

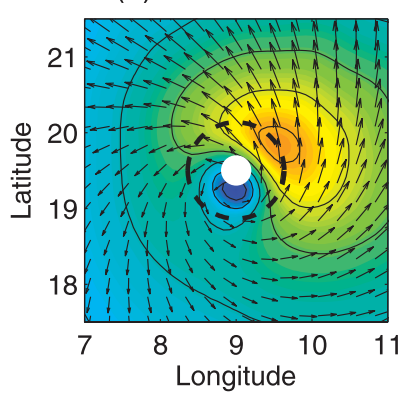

(c)

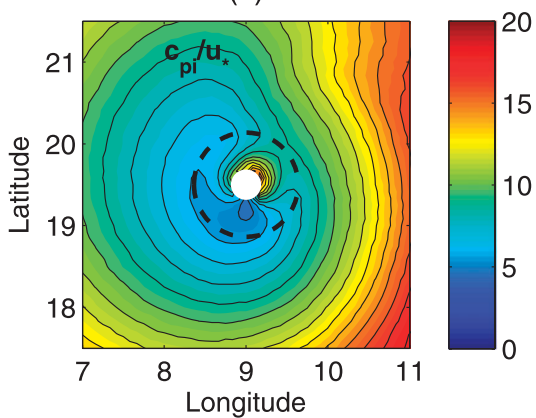

(e)

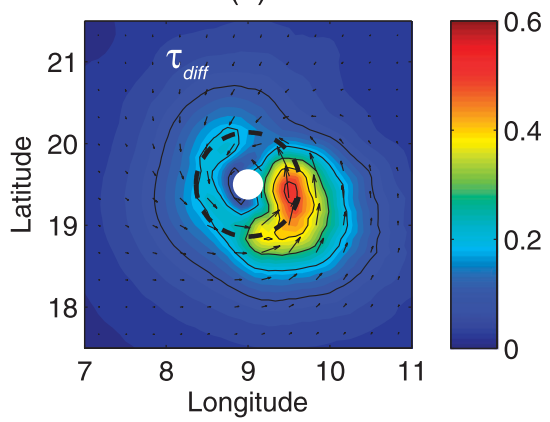

(b) $\mathrm{TSP}=10 \mathrm{~ms}^{-1}$

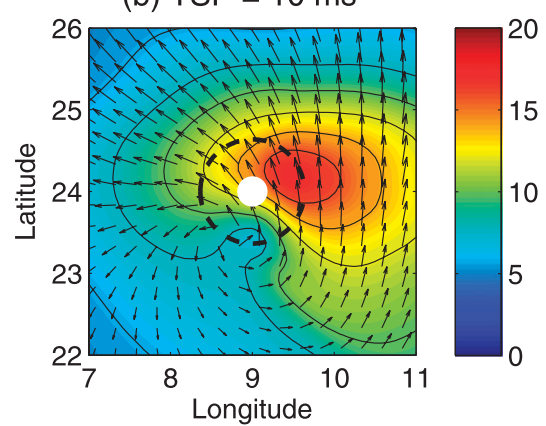

(d)

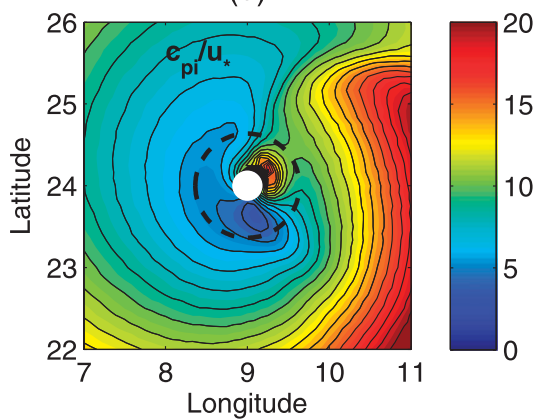

(f)

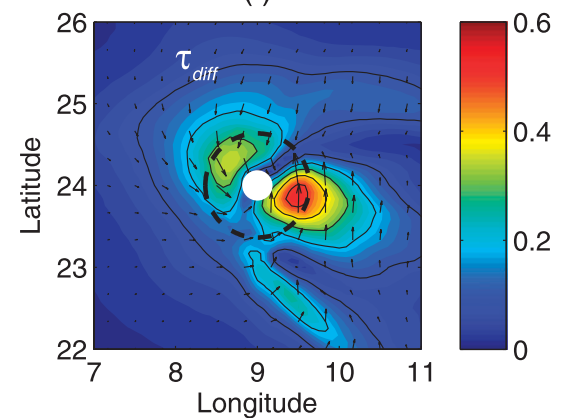

FIG. 7. (top) Significant wave height (color in meters) and mean wave direction and length (arrows) for moving TC with TSP = (a) 5 and (b) $10 \mathrm{~m} \mathrm{~s}^{-1}$; (middle) input wave age for moving TCs with TSP $=$ (c) 5 and (d) $10 \mathrm{~m} \mathrm{~s}^{-1}$; and (bottom) the net momentum flux gain/loss $\tau_{\text {diff }}$ [arrows; color scale shows the magnitude $\left(\mathrm{N} \mathrm{m}^{-2}\right)$ ] for the TSP $=$ (e) 5 and (f) $10 \mathrm{~m} \mathrm{~s}^{-1}$ experiments. The dashed circle and white dot represent the RMW and the center of the TC, respectively.

the RMW within the RMW and only slightly different at the storm periphery (Fig. 5e). From the $\left|\boldsymbol{\tau}_{\text {diff }}\right|$ versus input wave age plot in Fig. 5f, we can see that the $\left|\boldsymbol{\tau}_{\text {diff }}\right|$ values in all seven experiments collapse together and decrease rapidly with wave age, suggesting it is not sensitive to the changes in the RMW. Also notice that the $\left|\boldsymbol{\tau}_{\text {diff }}\right|$ values reach their maximum of about $0.3 \mathrm{~N} \mathrm{~m}^{-2}$ around the RMW, which is a significant fraction of the total wind stress (see section 6).

The effect of storm intensity on the momentum flux budget is investigated with different MWS of 35, 45, and $55 \mathrm{~m} \mathrm{~s}^{-1}$ (experiment B). The results are plotted against the normalized distance in Fig. 6e. The $\left|\boldsymbol{\tau}_{\text {diff }}\right|$ profiles along the radii direction again roughly follow the wind profile. The higher the MWS, the larger $\left|\tau_{\text {diff }}\right|$ is at the RMW. As the MWS increases, the $\left|\tau_{\text {diff }}\right|$ decreases more rapidly outside of the RMW. The $\left|\tau_{\text {diff }}\right|$ values in all three experiments again collapse together and decrease rapidly with input wave age (Fig. 6f), suggesting that, even though the maximum value of $\left|\boldsymbol{\tau}_{\text {diff }}\right|$ at the RMW increase with the MWS, the variation of $\left|\boldsymbol{\tau}_{\text {diff }}\right|$ with input wave age is not sensitive to the variation of MWS either.

\section{2) Moving TC}

The momentum flux budget under moving axisymmetric TCs is investigated in experiment $\mathrm{C}$. The spatial 

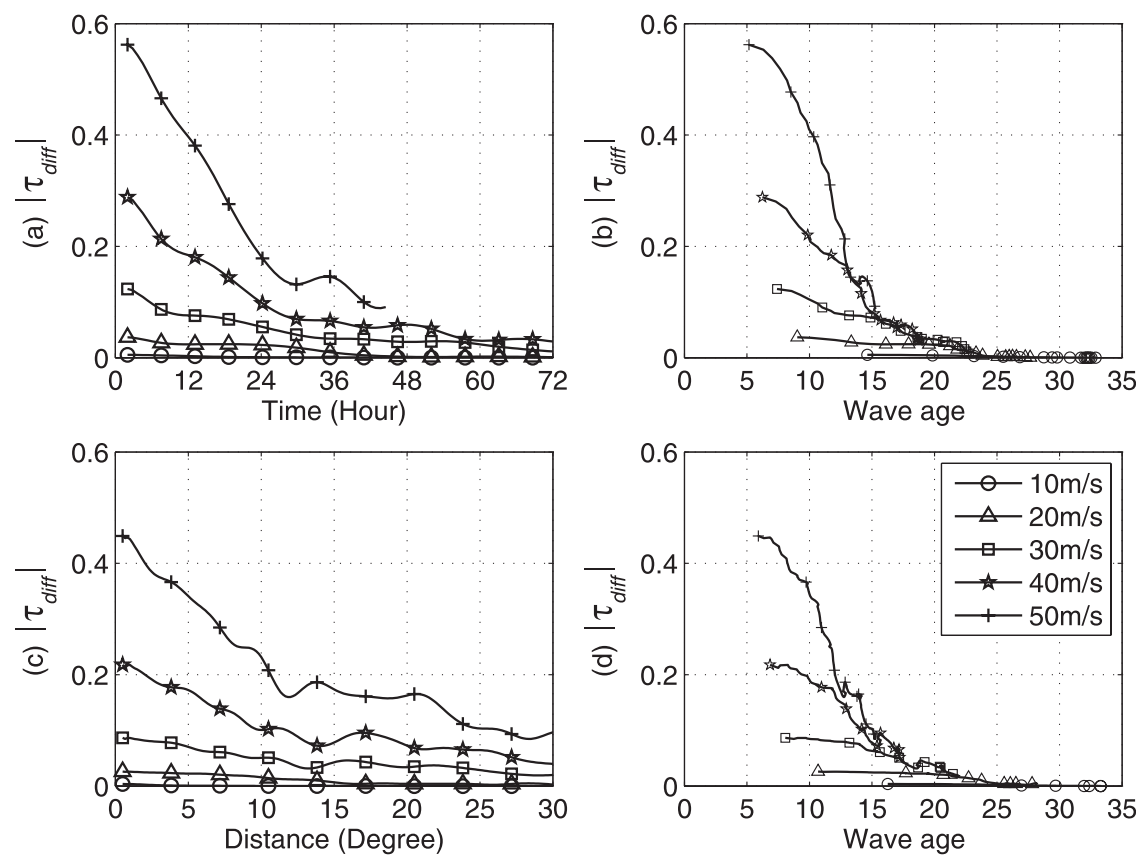

FIG. 8. Model results of (a) $\left|\tau_{\text {diff }}\right|$ vs dimensional time and (b) $\left|\tau_{\text {diff }}\right|$ vs the wave age in the time-dependent experiments and model results of (c) $\left|\tau_{\text {diff }}\right|$ vs dimensional distance and (d) $\left|\tau_{\text {diff }}\right|$ vs the wave age in the fetch-dependent experiments. Different symbols denote the simulations with steady homogenous winds of $10,20,30,40$, and $50 \mathrm{~m} \mathrm{~s}^{-1}$.

distribution of $\boldsymbol{\tau}_{\text {diff }}$ (net momentum gain/loss by the wave field) is shown in Figs. $7 \mathrm{e}$ and $7 \mathrm{f}$ for the storm moving at TSP of 5 and $10 \mathrm{~m} \mathrm{~s}^{-1}$, respectively. The color scale shows the absolute magnitude of the difference and the arrows show the vector difference. The waves reduce (increase) the momentum flux into subsurface currents relative to the flux from wind if the arrow is pointing to the same (opposite) direction as the wind. We can see that the major reduction of the momentum flux appears in the rear-right quadrant of the TC. Notice that $\left|\boldsymbol{\tau}_{\text {diff }}\right|$ peaks in three different areas for the fast moving TC (Fig. 7f). The maximum reduction of the momentum flux along the RMW is found to be similar for both experiments with different TSPs. These values $\left(\sim 0.6 \mathrm{~N} \mathrm{~m}^{-2}\right)$ are larger than in the stationary TC case $\left(\sim 0.3 \mathrm{~N} \mathrm{~m}^{-2}\right.$; see Fig. $\left.5 \mathrm{e}\right)$; that is, the wave effect on the momentum flux budget is enhanced by the TC movement.

\section{Reduction of momentum flux into the ocean relative to wind stress}

In this section, the ratio of $\left|\boldsymbol{\tau}_{c}\right| /\left|\boldsymbol{\tau}_{\text {air }}\right|$ is analyzed. This ratio provides a measure of how much a growing surface wave field reduces the momentum flux into subsurface currents relative to the wind stress. Since this calculation explicitly depends on the drag coefficient parameterization, we first summarize the uncertainty of the drag coefficient at high wind speeds.

Over the last several decades, many field measurements, laboratory experiments, and modeling works were conducted to study the behavior of drag coefficient $C_{d}$ under different wind speeds. Figure 9 combines $C_{d}$ derived from field observations under medium wind conditions (less than $20 \mathrm{~m} \mathrm{~s}^{-1}$ ) by Drennan et al. (1996, 2003) and under TC conditions by French et al. (2007) and Powell (2007). In addition, the commonly used Large and Pond (1981) empirical wind-speed-dependent formula is also included. We can see that there is a wide range of $C_{d}$ from all of these studies under high wind conditions. The drag produced by the CWW is in the middle to higher range. The upper and lower boundaries of the $C_{d}$ range are empirically determined and are shown by the black dashed lines in Fig. 9. Here we estimate the ratio of $\left|\boldsymbol{\tau}_{c}\right| /\left|\boldsymbol{\tau}_{\text {air }}\right|$ using the CWW estimations of $\boldsymbol{\tau}_{\text {air }}$, as well as the $\tau_{\text {air }}$ calculated using the upper and lower boundaries of $C_{d}$ shown in Fig. 9.

Note that the same $\tau_{\text {diff }}$ estimated in section 5 will be used in the calculation of $\tau_{c}$ relative to the upper and lower bound of $\tau_{\text {air }}$. In theory, changing $\tau_{\text {air }}$ will also modify the resulting wave modeling and $\boldsymbol{\tau}_{\text {diff. }}$. However, since the wave field simulated by the wave model has been carefully validated against observations, we assume that the sum of the three forcing terms (wind forcing, 


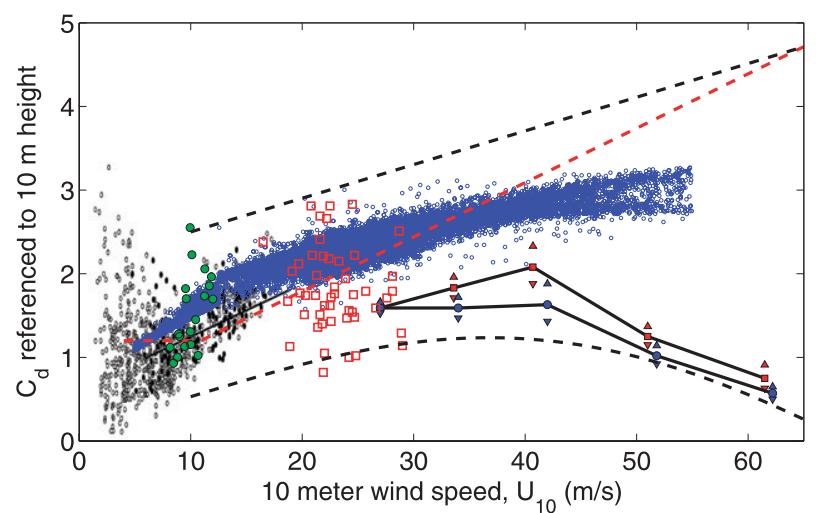

FIG. 9. Drag coefficient $C_{d}$ comparison from different studies. The black circles and dots in the back ground are field measurements presented in Fig. 4 of Drennan et al. (2003). The green circles are field measurements from Drennan et al. (1996). The red open squares are Coupled Boundary Layer Air-Sea Transfer Experiment (CBLAST) field measurements from French et al. (2007). The red dashed line is the Large and Pond (1981) wind-speeddependent formula. The black line with red squares (blue dots) shows the drag coefficient estimated by Powell (2007) based on the 20-160-m (10-160 m) surface layers, and the upward and downward pointing red (blue) triangles indicate the $95 \%$ confidence limits on the estimates. The blue circles are $C_{d}$ from the CWW in the experiments conducted in this paper. The black dashed lines give the upper and lower boundary of $C_{d}$ from all the studies shown here.

nonlinear interaction, and dissipation) used in the wave model is sufficiently accurate, even if the individual terms may not be necessarily correct. We then assume that, if $\tau_{\text {air }}$ and the resulting wind input to waves are modified, the wave dissipation term must be modified (retuned) simultaneously such that the resulting wave field remains consistent with observations. Therefore, we will investigate the $\left|\boldsymbol{\tau}_{c}\right| /\left|\boldsymbol{\tau}_{\text {air }}\right|$ without modifying $\boldsymbol{\tau}_{\text {diff. }}$.

\section{a. Steady uniform wind}

The ratios of $\left|\boldsymbol{\tau}_{c}\right| /\left|\boldsymbol{\tau}_{\text {air }}\right|$ against wave age for the durationdependent (left) and fetch-dependent (right) experiment is presented in Fig. 10. The black lines with different symbols are estimated using $\boldsymbol{\tau}_{\text {air }}$ calculated from CWW, and the gray shaded area shows the range of this ratio corresponding to the $\tau_{\text {air }}$ calculated using the upper and lower bounds of the drag coefficient in Fig. 9. Note that, as $\left|\boldsymbol{\tau}_{\text {diff }}\right|$ is uniquely determined by the simulated wave field, the variability of $\left|\boldsymbol{\tau}_{c}\right| /\left|\boldsymbol{\tau}_{\text {air }}\right|$ is solely due to the variability of $\left|\boldsymbol{\tau}_{\text {air }}\right|$. We can see that this ratio is very similar between the duration-dependent and fetch-dependent cases. Generally, the higher the wind speed and the younger the wave field, the lower this ratio. The variation of the ratio is large in high wind conditions owing to the large uncertainty of the drag coefficient. For example, for the $50 \mathrm{~m} \mathrm{~s}^{-1}$ wind at wave age 5 , the ratio can be as low as $78 \%$ if the wind stress is as low as the observations by Powell (2007) and as high as $95 \%$ if the wind stress is as high as the Large and Pond (1981) formulas. Nevertheless, it is clear that surface waves may significantly reduce the momentum flux into currents relative to the wind stress at high wind speeds and lower wave ages.

\section{b. Stationary $T C$}

Figure 11a shows the ratio of $\left|\boldsymbol{\tau}_{c}\right|$ relative to $\left|\boldsymbol{\tau}_{\text {air }}\right|$ for experiment A. The black lines with different symbols are estimated using $\boldsymbol{\tau}_{\text {air }}$ calculated from the CWW, and the gray shaded area shows the range of the ratio corresponding to the $\tau_{\text {air }}$ calculated using the upper and lower bounds of the drag coefficient shown in Fig. 9. The reduction of the momentum flux into currents is the largest near the RMW, where $\left|\boldsymbol{\tau}_{c}\right| /\left|\boldsymbol{\tau}_{\text {air }}\right|$ is between $90 \%$ and $97 \%$, depending on the drag coefficient. This result confirms that the spatial variation of the wave field has a significant effect on the air-sea momentum flux budget under a stationary TC.

The ratio of $\left|\boldsymbol{\tau}_{c}\right|$ relative to $\left|\boldsymbol{\tau}_{\text {air }}\right|$ in experiment B is presented in Figs. 11b-d. When the MWS is increased to $55 \mathrm{~m} \mathrm{~s}^{-1}$, the ratio $\left|\boldsymbol{\tau}_{c}\right| /\left|\boldsymbol{\tau}_{\text {air }}\right|$ varies between $80 \%$ and $96 \%$ near the RMW, depending on the drag coefficient. This suggests that for stronger hurricanes the reduction of the momentum flux into the subsurface current relative to the wind stress can be significantly enhanced.

\section{c. Moving TC}

The ratio $\left|\boldsymbol{\tau}_{c}\right| /\left|\boldsymbol{\tau}_{\text {air }}\right|$ for the TC moving at TSPs of 5 and $10 \mathrm{~m} \mathrm{~s}^{-1}$ is presented in Fig. 12. The middle panels show the ratio calculated using $\tau_{\text {air }}$ produced by the CWW model, and the top (bottom) panels show the upper (lower) boundary of the ratio. The major reduction of the momentum flux appears in the rear-right quadrant of the TC. In particular, near the RMW, the momentum flux into currents is reduced to $84 \%-95 \%$ relative to the wind stress. Therefore, the movement of the TC may further enhance the reduction of the momentum flux due to surface waves.

In all previous experiments, the wind fields are assumed to be axisymmetric. However, when a TC moves, the actual wind speed to the right (left) of its track becomes higher (lower) because of addition (subtraction) of the TSP to the wind speed determined by the TC pressure field. The maximum wind speed is therefore usually found on the right-hand side of the TC. In experiment $\mathrm{D}$ we investigate the effect of asymmetric wind fields on the momentum flux budget by adding half of the TC TSP to the symmetric wind field produced by the Holland model. We found that the asymmetry of the wind field did not make any qualitative changes in the momentum flux budgets. The wave parameters and the ratio 

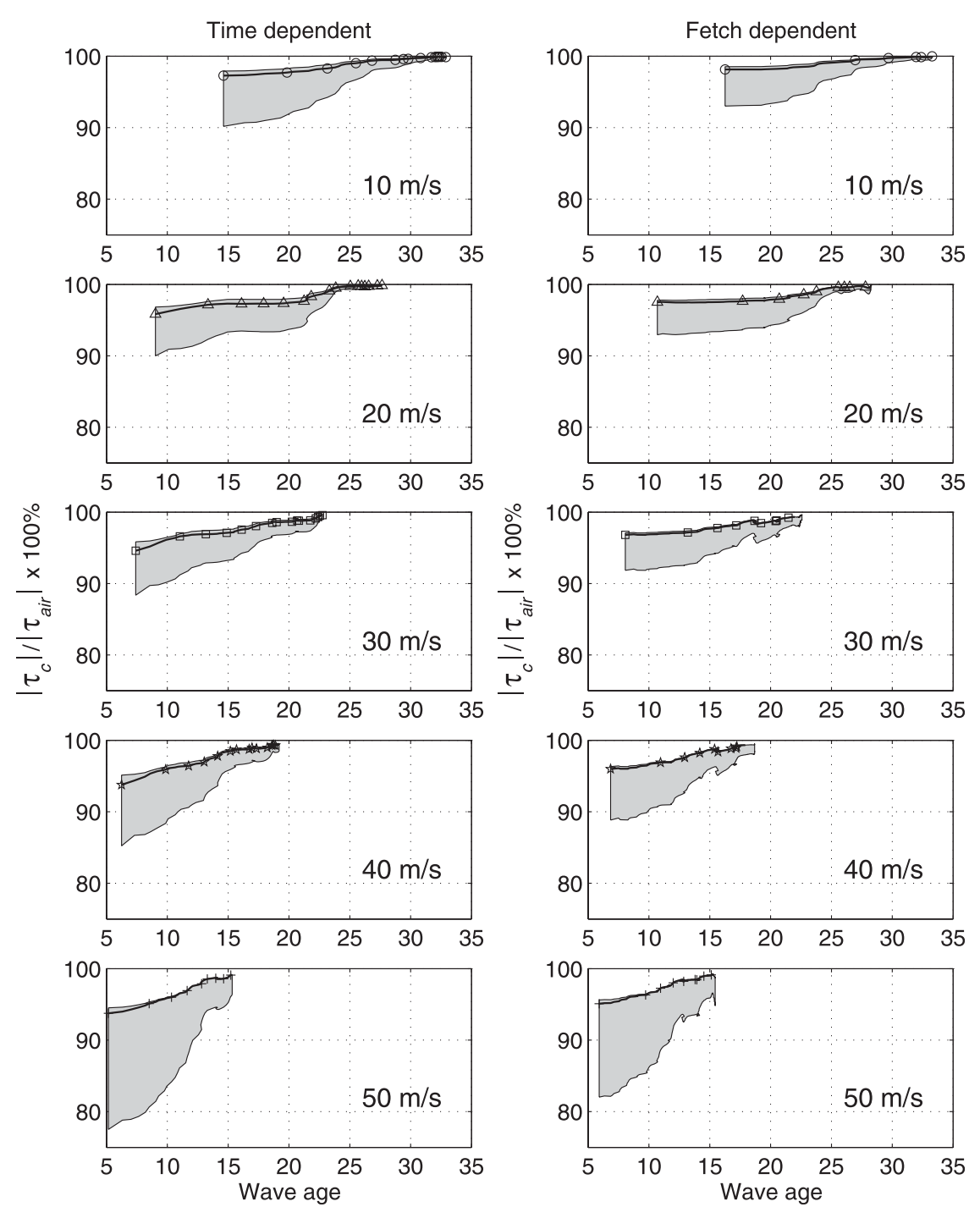

FIG. 10. Model results of $\left|\tau_{c}\right| /\left|\tau_{\text {air }}\right|$ vs the wave age in the (left) time-dependent and (right) fetch-dependent experiments for simulations with steady homogenous winds of (from top to bottom) 10, 20, 30, 40, and $50 \mathrm{~m} \mathrm{~s}^{-1}$. The shaded area shows the variation of the percentage results due to the upper and lower bounds of $C_{d}$. Symbols as in the legend for Fig. 4.

of $\left|\boldsymbol{\tau}_{c}\right| /\left|\boldsymbol{\tau}_{\text {air }}\right|$ are hardly changed between experiments D and $\mathrm{C}$ for both TSPs (not shown).

\section{Summary and conclusions}

The effect of surface gravity waves on the momentum flux budget across the air-sea interface has been investigated in a series of numerical experiments. An airsea momentum flux budget model is formulated to estimate the difference, $\boldsymbol{\tau}_{\text {diff }}$, between the momentum flux from air, $\boldsymbol{\tau}_{\text {air }}$, and the flux to subsurface currents, $\boldsymbol{\tau}_{c}$. We have considered steady uniform wind and tropical cyclone (TC) wind conditions. The wave fields are simulated using the NOAA WAVEWATCH III (WWIII) wave model with a modified momentum flux parameterization based on the coupled wave-wind (CWW) model of Moon et al. (2004a,b).

The uniform wind problem is investigated for both duration- and fetch-dependent cases with wind speeds varying from 10 to $50 \mathrm{~m} \mathrm{~s}^{-1}$ using an increment of $10 \mathrm{~m} \mathrm{~s}^{-1}$. We found that the higher the wind speed and the younger the wave field, the larger the difference between the flux from wind and the flux to currents. For higher wind speed $\left(U_{10} \geq 30 \mathrm{~m} \mathrm{~s}^{-1}\right)$, the difference decreases rapidly with wave age before wave age 15 . The reduction of the momentum flux into currents relative to the wind stress is significant at higher wind speeds and at lower wave ages, although it strongly depends on the 
(a)

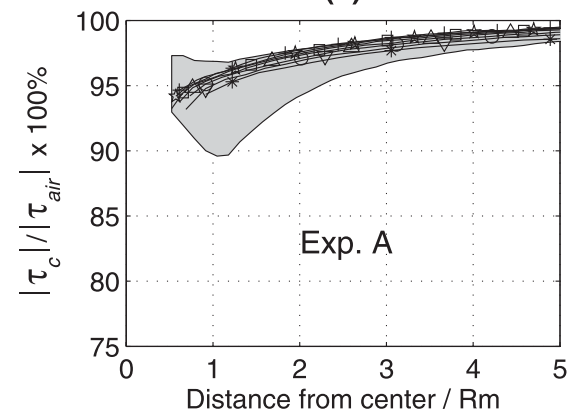

(c)

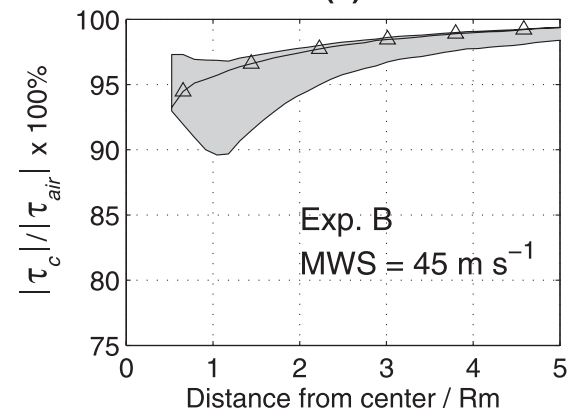

(b)

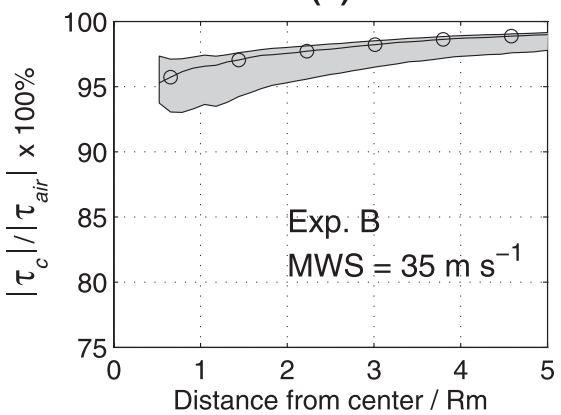

(d)

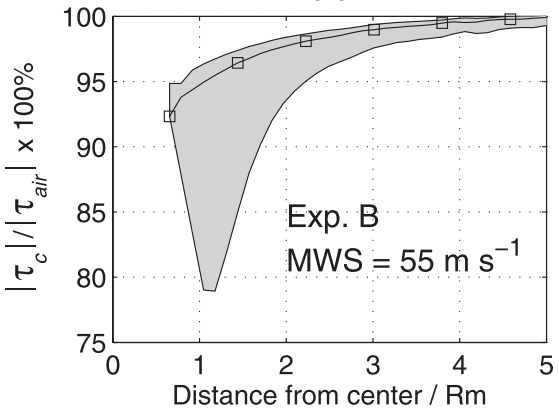

FIG. 11. Model results of $\left|\tau_{c}\right| /\left|\tau_{\text {air }}\right|$ vs normalized distance from center in (a) all cases in expt A, (b) MWS $=35 \mathrm{~m} \mathrm{~s}^{-1}$ case in expt B, (c) MWS $=45 \mathrm{~m} \mathrm{~s}^{-1}$ case in expt B, and (d) MWS = $55 \mathrm{~m} \mathrm{~s}^{-1}$ case in expt B. The symbols in (a) are as in the legend for Fig. 6. The shaded area in all panels shows the variation of the percentage results due to the upper and lower bounds of $C_{d}$.

choice of the drag coefficient parameterization. The ratio of $\left|\boldsymbol{\tau}_{c}\right| /\left|\boldsymbol{\tau}_{\text {air }}\right|$ is estimated to be $78 \%-95 \%$ for the $50 \mathrm{~m} \mathrm{~s}^{-1}$ wind at wave age 5 .

The TC wind conditions are investigated using an idealized TC with different translation speeds (TSPs), intensities, and structure. The results suggest that surface waves may significantly reduce the momentum flux into currents relative to the wind stress. For stationary hurricanes, the reduction is enhanced as the MWS increases. When the MWS reaches $55 \mathrm{~m} \mathrm{~s}^{-1}$, the ratio $\left|\boldsymbol{\tau}_{c}\right| /\left|\boldsymbol{\tau}_{\text {air }}\right|$ near the RMW is estimated to be between $80 \%$ (for low drag coefficient) and 96\% (for high drag coefficient). When a TC moves, the wave field becomes asymmetric with higher and longer waves in the frontright quadrant of the TC and lower and shorter waves in the rear-left quadrant. The asymmetry of the wave field further reduces the momentum flux into subsurface currents in the rear-right quadrant of the TC.

The results of this study clearly demonstrate that surface gravity waves may play an important role in the airsea momentum flux budget in TCs, in particular, if the drag coefficient is low at high wind speeds as suggested by recent observations (Powell 2007). These findings suggest that it may be essential to include the surface wave effects with the explicit air-sea flux budget calculations in coupled TC-ocean prediction models. In fact, Fan et al. (2009a) have recently performed detailed investigations on the effect of wind wave-current interaction mechanisms in TCs and their effect on the surface wave and ocean responses through a set of numerical experiments. They found that the reduction of the momentum flux into the ocean consequently reduces the magnitude of the subsurface current and sea surface temperature cooling to the right of the hurricane track and the rate of upwelling/ downwelling in the thermocline.

In this study, we have not investigated the impact of different drag coefficient parameterizations on the wave simulations. However, in our earlier study (Fan et al. 2009b) we found that the simulated significant wave heights under a strong tropical cyclone are reduced by up to $10 \%-20 \%$ when the original WWIII drag parameterization is replaced by the CWW parameterization. Note that, although the original WWIII drag coefficient is more than a factor of 2 larger than in the CWW parameterization for winds higher than $40 \mathrm{~m} \mathrm{~s}^{-1}$, they are very similar for winds less than $20 \mathrm{~m} \mathrm{~s}^{-1}$ (Fig. 6 in Moon et al.2004b). Typically, the spatial area of very high wind speeds (i.e., vicinity of the RMW) is relatively small compared to the overall area influenced by a tropical cyclone. Therefore, a particular wave field cannot be exposed to very high wind speeds for an extended time period under a tropical cyclone, and the significant wave 
(a) $\mathrm{TSP}=5 \mathrm{~ms}^{-1}$

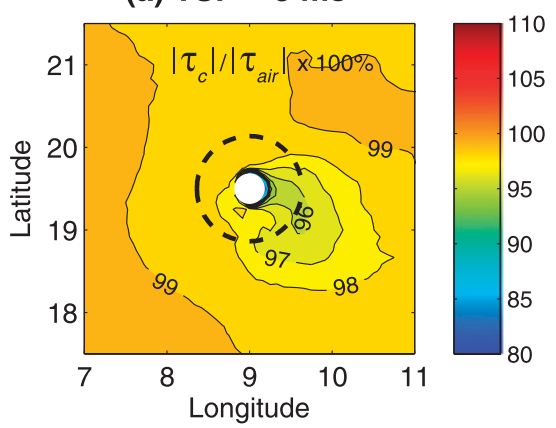

(c) $\mathrm{TSP}=5 \mathrm{~ms}^{-1}$

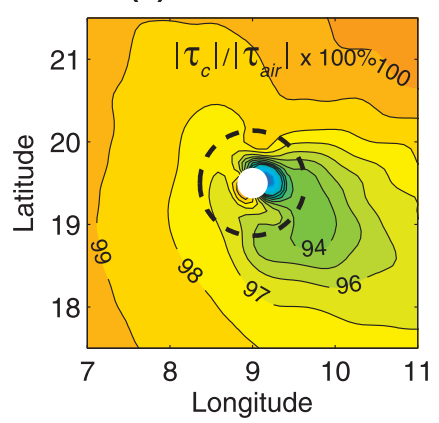

(e) TSP $=5 \mathrm{~ms}^{-1}$

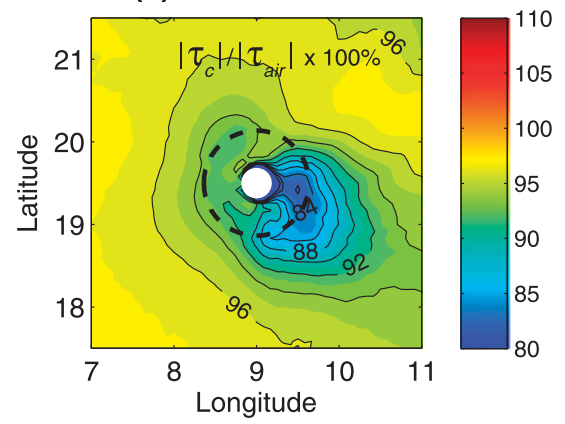

(b) TSP $=10 \mathrm{~ms}^{-1}$

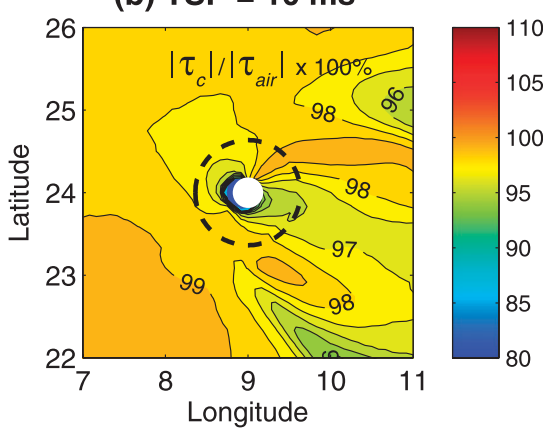

(d) $\mathrm{TSP}=10 \mathrm{~ms}^{-1}$
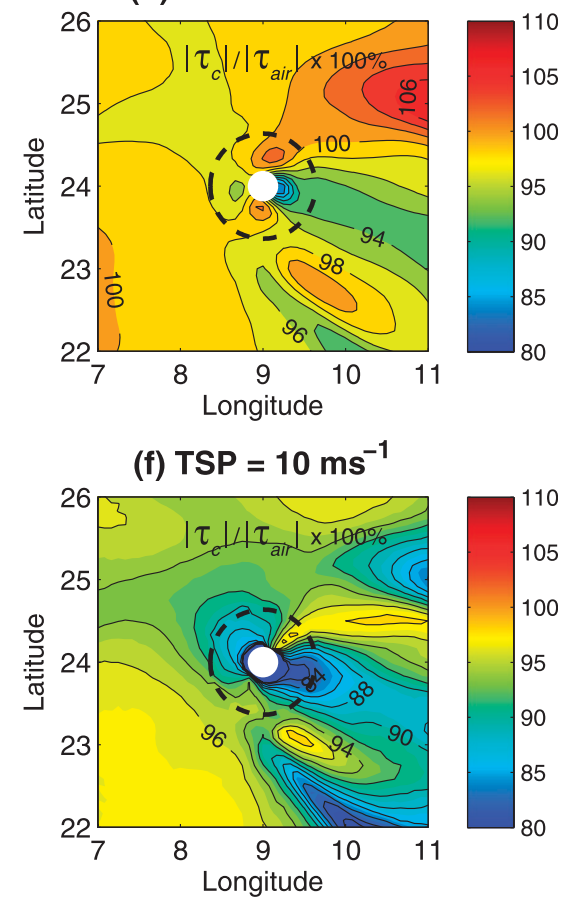

FIG. 12. The percentage of the magnitude of momentum flux into currents $\left|\tau_{c}\right|$ relative to the magnitude of the momentum flux from air $\left|\tau_{\text {air }}\right|$ for experiments with TSP $=$ (left) $5 \mathrm{~m} \mathrm{~s}^{-1}$ and (right) $10 \mathrm{~m} \mathrm{~s}^{-1}$ : (a),(b) corresponding to the upper bound of $C_{d}$; (c),(d) calculated using $C_{d}$ from the CWW model; and (e),(f) corresponding to the lower bound of $C_{d}$. The black dashed circle in the figure indicates the RMW; the white dot is the center of the storm.

height does not increase as much as the local wind stress, even in the vicinity of the RMW. Fan et al. (2009b) also found that the WWIII simulations of the significant wave heights with different drag parameterizations under Hurricane Ivan (2004) differed from each other and observations by $10 \%-20 \%$. As $\boldsymbol{\tau}_{\text {diff }}$ is solely determined by the wave field, we speculate that it is not very sensitive to the choice of the particular drag coefficient parameterization.

Acknowledgments. This work was supported by the U.S. National Science Foundation through Grants ATM 0406895 and WeatherPredict Consulting Inc. via a grant to the URI Foundation. TH and IG also thank the U.S. Office of Naval Research (CBLAST program, Grant N00014-0610729) and the Korea Research and Development Institute (Grant 500-2802-0000-0001377) for additional support.

\section{APPENDIX A}

\section{Normalized Wave Parameters in Steady Uniform Wind Experiments}

In this appendix, we investigate the normalized wave parameters produced by the WWIII model in the steady 

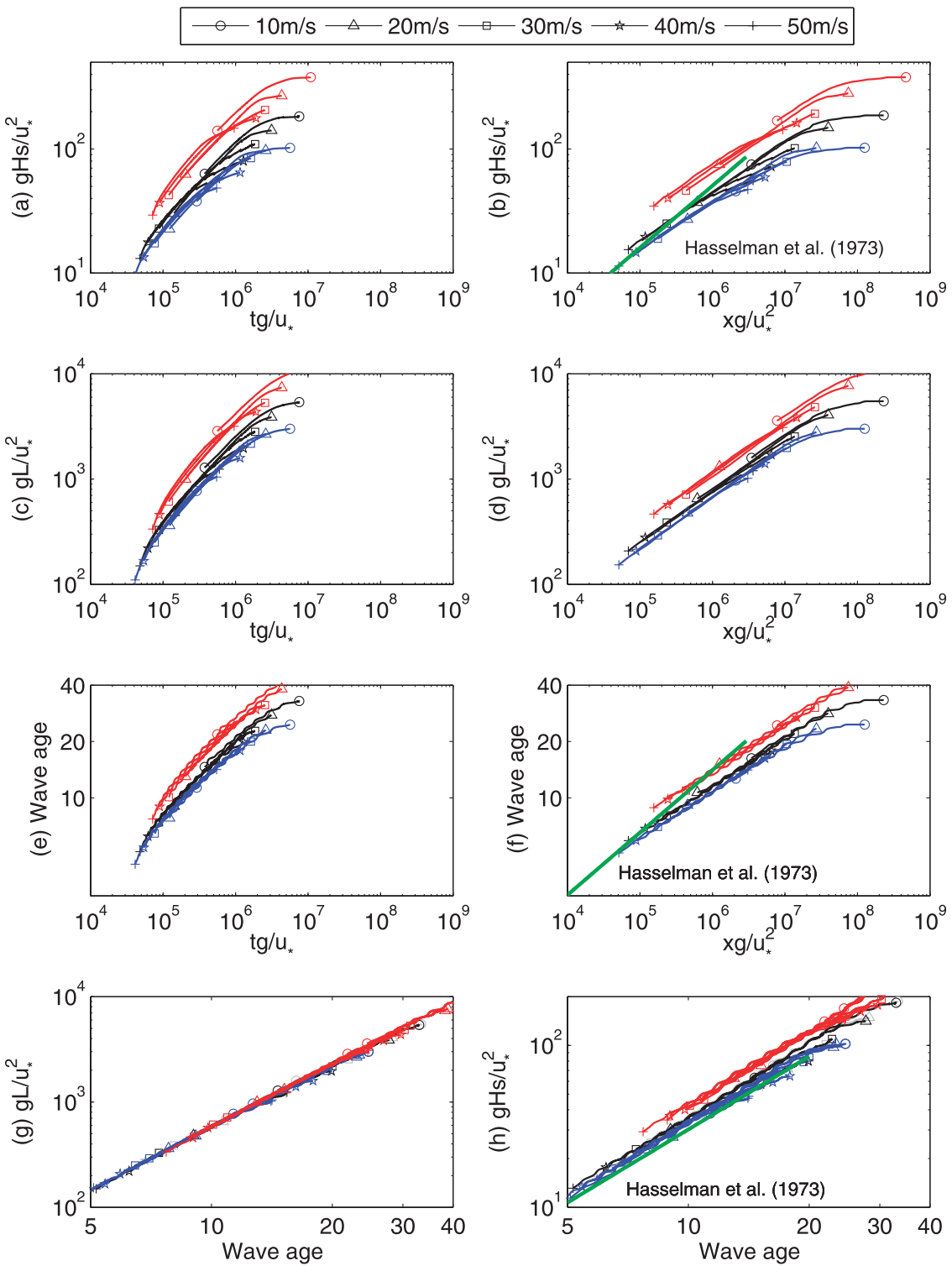

FIG. A1. (a) Normalized significant wave height vs normalized duration, (b) normalized significant wave height vs normalized fetch, (c) normalized mean wavelength vs normalized duration, (d) normalized mean wavelength vs normalized fetch, (e) wave age vs normalized duration, (f) wave age vs normalized fetch, (g) normalized mean wavelength vs wave age, and (h) normalized significant wave height vs wave age; both time-dependent and fetch-dependent simulations in (f),(g). Black lines are wave parameters normalized using the CWW drag parameterization, red lines are wave parameters normalized using the drag parameterization at the lower boundary in Fig. 9, and blue lines are wave parameters normalized using the drag parameterization at the upper boundary in Fig. 9. The green lines show the empirical formula from Hasselman et al. (1973) for wave age less than 20 (see details in text). All results are simulated with steady homogenous winds of 10,20,30,40, and $50 \mathrm{~m} \mathrm{~s}^{-1}$ (as shown by different symbols in the legend).

uniform wind experiments. We normalize the significant wave height and mean wavelength as $g H_{s} / u_{*}^{2}$ and $g L / u_{*}^{2}$ and examine how these two nondimensional parameters and the wave age $c_{p} / u_{*}$ vary with the normalized duration (defined as $g t / u_{*}$ ) or the normalized fetch (defined as $\left.g x / u_{*}\right)$. First, we use the friction velocity $u_{*}$ estimated using the CWW model in the normalizations. Figure A1 (black) shows that all three parameters $\left(g H_{s} / u_{*}^{2}, g L / u_{*}^{2}\right.$, 
and $\left.c_{p} / u_{*}\right)$ are related to $g t / u_{*}$ or $g x / u_{*}$ with simple power-law dependence, except toward the very end of the wave development (after wave age is greater than 20) when the waves gradually approach the fully grown state. This clearly indicates that the growing wave field simulated by WWIII is self-similar as far as the significant wave height, mean wavelength, and wave age are concerned. The relationships between $g H_{s} / u_{*}^{2}$ and $c_{p} / u_{*}$ as well as between $g L / u_{*}^{2}$ and $c_{p} / u_{*}$ are shown in Figs. A1h and A1g for both the duration- and fetch-dependent experiments. Clearly, both $g H_{s} / u_{*}^{2}$ and $g L / u_{*}^{2}$ are uniquely related to $c_{p} / u_{*}$ with simple power laws.

Next, we examine how the results are affected by the uncertainty of the drag coefficient discussed in section 6 . The calculations of $g H_{s} / u_{*}^{2}, g L / u_{*}^{2}, c_{p} / u_{*}, g t / u_{*}$, and $g x / u_{*}$ are made using the same wave parameters but with the upper and lower bounds of $u_{*}$ determined in section 6 . The results are also shown in Fig. A1 (red and blue). Although the results are shifted depending on the choice of the drag coefficient, the power-law relationships seem to hold in all cases.

In the past studies, power-law relationships among $g x / u_{*}$, $g H_{s} / u_{*}^{2}$, and $c_{p} / u_{*}$ were obtained empirically from field and laboratory observations. The well-known formulas from Hasselman et al. (1973) are given for waves up to wave age 20 as

$$
\frac{g H_{s}}{u_{*}^{2}}=0.0506\left(\frac{g x}{u_{*}^{2}}\right)^{1 / 2}
$$

and

$$
\frac{u_{*} \omega_{p}}{g}=7.1\left(\frac{g x}{u_{*}^{2}}\right)^{-1 / 3}
$$

where $\omega_{p}$ is the peak frequency.

Combining (A1) and (A2) with $c_{p}=g / \omega_{p}$, we obtain

$$
\frac{g H_{s}}{u_{*}^{2}}=0.9572\left(\frac{c_{p}}{u_{*}}\right)^{3 / 2} .
$$

These formulas are also shown in Figs. A1b,f,h (green lines). It is seen that the relationship between $g x / u_{*}$ and $g H_{s} / u_{*}^{2}$ and the relationship between $g x / u_{*}$ and $c_{p} / u_{*}$ in the model shows slightly less steepness than the empirical relationship by Hasselman et al. (1973). To avoid the uncertainty brought in by $u_{*}$, Donelan et al. (1992) developed an analytical solution of the growth functions in terms of normalized fetch $\left(g x / U_{10}^{2}\right)$,

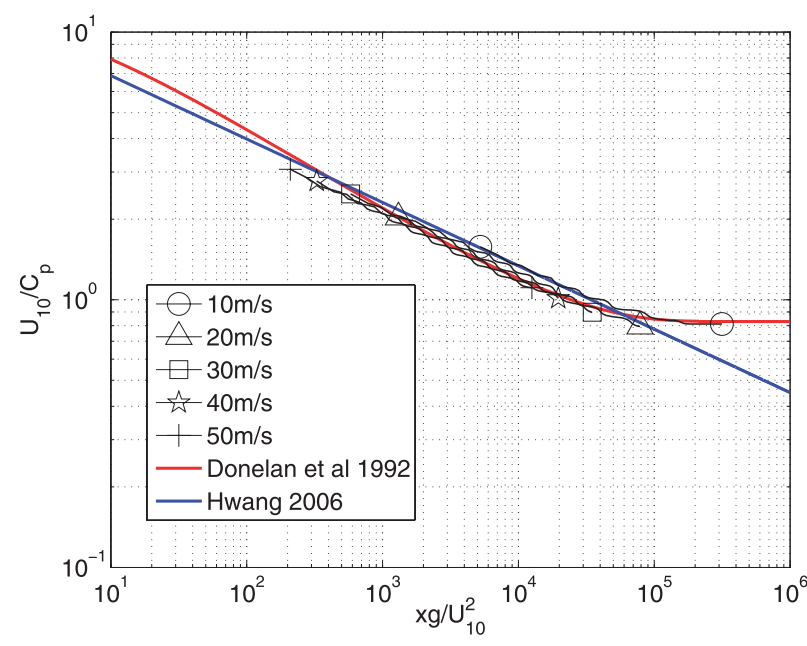

FIG. A2. Plot of $U_{10} / C_{p}$ vs normalized duration. The red line shows the empirical formula from Donelan et al. (1992); the blue line the empirical formula from Hwang (2006). All results are simulated with steady homogenous winds of $10,20,30,40$, and $50 \mathrm{~m} \mathrm{~s}^{-1}$ (as shown by different symbols in the legend).

$$
\begin{aligned}
\frac{g x}{U_{10}^{2}}= & 4.0946 \times 10^{4} \ln \left(\frac{U_{10} / c_{p}}{U_{10} / c_{p}-0.8302}\right) \\
& -3.3992 \times 10^{4}\left(U_{10} / c_{p}+0.4151\right)\left(U_{10} / c_{p}\right)^{2} .
\end{aligned}
$$

Hwang (2006) further simplified this relation and proposed a higher-order data fitting technique to represent wave growth in power-law functions,

$$
\frac{U_{10}}{c_{p}}=11.86\left(\frac{g x}{U_{10}^{2}}\right)^{-0.2368} .
$$

These two formulas are also compared with the fetchdependent model results in Fig. A2. We can see that the Hwang (2006) curve (blue line) is close to the Donelan et al. (1992) curve (red line) with slightly different slope when $g x / U_{10}^{2}<10^{5}$, and the two curves split when $g x / U_{10}^{2}>10^{5}$. Our model results compare very well with Donelan et al. (1992) and split from the Hwang (2006) curve when $g x / U_{10}^{2}>10^{5}$. We can also see that the model relationship between $c_{p} / u_{*}$ and $g H_{s} / u_{*}^{2}$ has the same slope as the empirical formulas, regardless of the choice of the drag coefficient (Fig. A1h).

\section{APPENDIX B}

\section{Sensitivity of $\tau_{\text {diff }}$ to Spectrum Tail Parameterization}

In this appendix, we investigate the sensitivity of the difference between the momentum flux from wind and 

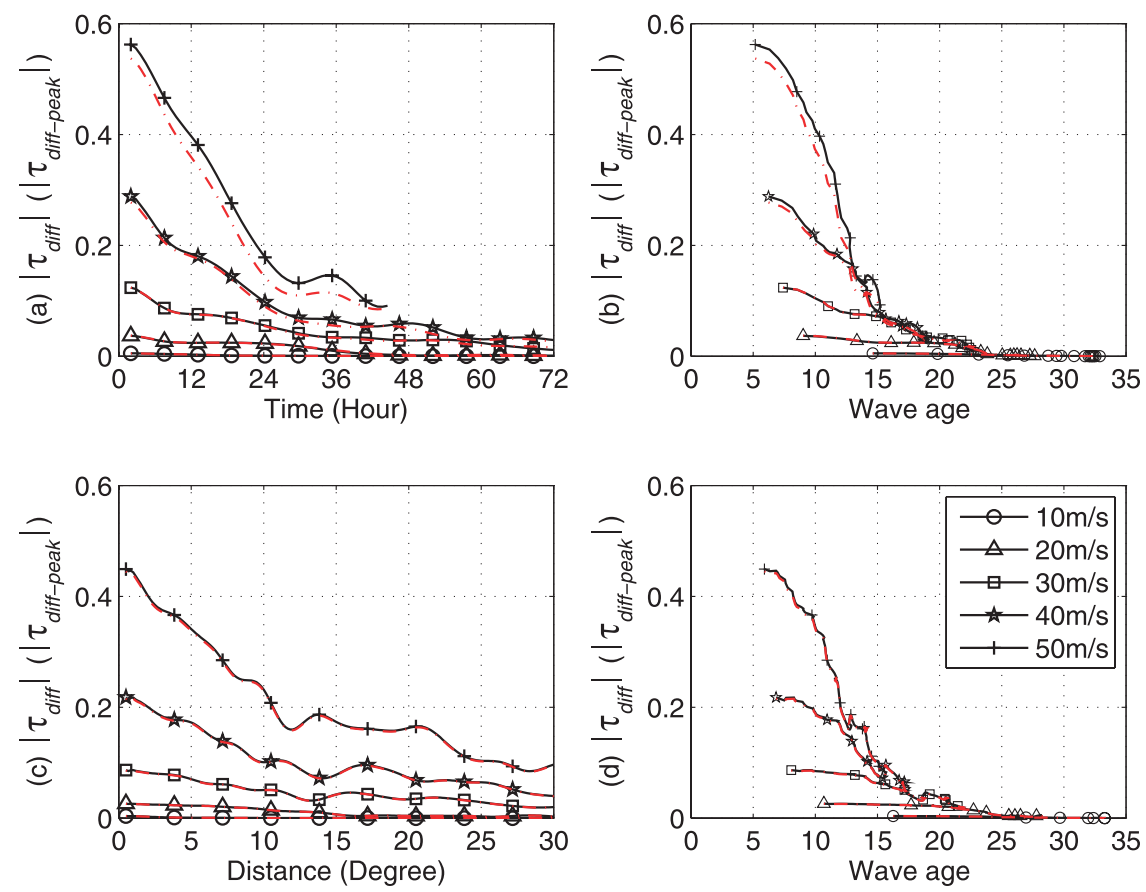

FIG. B1. Model results of $\left|\tau_{\text {diff }}\right|$ (black lines) and $\left|\tau_{\text {diff-peak }}\right|$ (red lines) vs (a) dimensional time and (b) the wave age in the time-dependent experiments and (c) dimensional distance and (d) the wave age in the fetch-dependent experiments. Different symbols denote the simulations with steady homogenous winds of $10,20,30,40$, and $50 \mathrm{~m} \mathrm{~s}^{-1}$.

the flux into subsurface currents to the parameterization of the spectrum tail in the WWIII wave model. To do this, we calculate the total momentum $\left(M T_{x}\right.$ and $\left.M T_{y}\right)$ and momentum flux $\left(M F_{x x}, M F_{x y}, M F_{y x}\right.$, and $\left.M F_{y y}\right)$ in the wave field using the WWIII-resolved spectrum only [i.e., in Eqs. (7)-(12), we only integrate the model-resolved wave spectrum in the frequency range resolved in the WWIII; no spectrum tail is attached in this calculation]. Then, we estimate the difference between the momentum flux from wind and the flux into subsurface currents based on the resolved part of the spectrum only, $\tau_{\text {diff-peak }}$.

The $\left|\boldsymbol{\tau}_{\text {diff-peak }}\right|$ for both duration- and fetch-dependent experiments are presented in Fig. B1 E-MAIL ROGER RE APP NUMBERby the red dashed lines. The results are shown against both dimensional time/space (left) and the wave age (right). The results of $\left|\boldsymbol{\tau}_{\text {diff }}\right|$ in Fig. 8 are also given by the black lines for reference. We can see that the results of $\left|\boldsymbol{\tau}_{\text {diff-peak }}\right|$ and $\left|\boldsymbol{\tau}_{\text {diff }}\right|$ are very close for both experiments at all wind speeds. The comparison of $\left|\boldsymbol{\tau}_{\text {diff-peak }}\right|$ (red dashed line) and $\left|\boldsymbol{\tau}_{\text {diff }}\right|$ (black) versus radii distance from the center (left) and the wave age (right) for experiments A and B are shown in Fig. B2. Again, we can see that $\left|\boldsymbol{\tau}_{\text {diff-peak }}\right|$ and $\left|\boldsymbol{\tau}_{\text {diff }}\right|$ are almost identical for the stationary TC experiments. These experiments have verified that the results of $\left|\boldsymbol{\tau}_{\text {diff }}\right|$ are not sensitive to different choices of the spectral tail.

\section{APPENDIX C}

\section{Consistency between the Air-Sea Budget Analysis of this Study and Other Wave-Current Theories}

In this appendix we show that the effect of surface waves on the air-sea momentum flux budget as discussed in this study is consistent with other wave-current theories. Recently, several theories of wave-current interaction have been developed (e.g., Mellor 2003, 2005, 2008; Ardhuin et al. 2008; McWilliams and Restrepo 1999). Although there is yet no definite consensus regarding the most accurate set of equations, the theory of Mellor (2008), which was developed in response to the study of Ardhuin et al. (2008), appears to be one of the more complete descriptions of the wave-current interactions. Although the theory was formally derived for a single wave train, it can likely be extended to include a spectrum of waves.

Following Mellor (2008), the horizontal momentum equation of the ocean model is written as

$$
\begin{gathered}
\frac{\partial}{\partial t} U_{\alpha}+\frac{\partial}{\partial x_{\beta}}\left(U_{\alpha} U_{\beta}\right)+\frac{\partial}{\partial z}\left(W U_{\alpha}\right)-\varepsilon_{\alpha \beta z} f U_{\beta} \\
=-\frac{1}{\rho} \frac{\partial P}{\partial x_{\alpha}}-\frac{\partial}{\partial x_{\beta}} S_{\alpha \beta}+\frac{\partial \bar{\tau}_{t \alpha}}{\partial z}+\frac{\partial \bar{\tau}_{p \alpha}}{\partial z},
\end{gathered}
$$


(a)

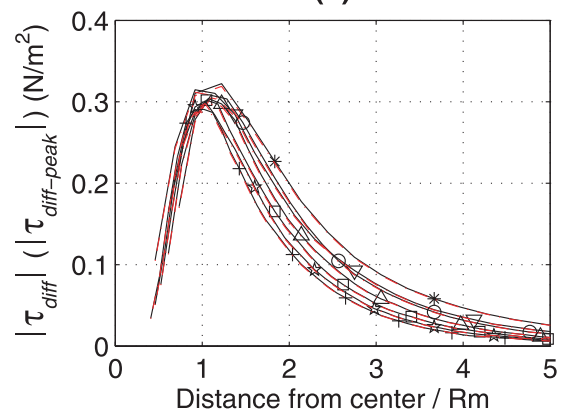

(c)

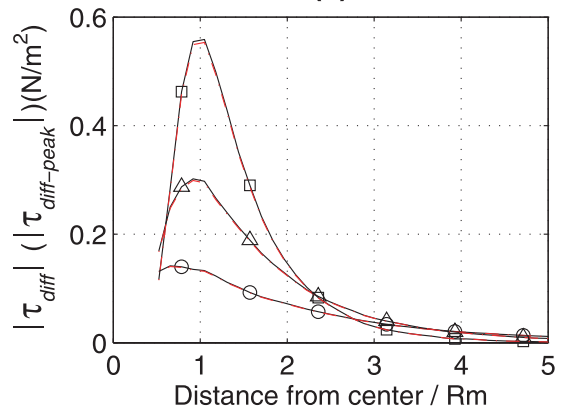

(b)

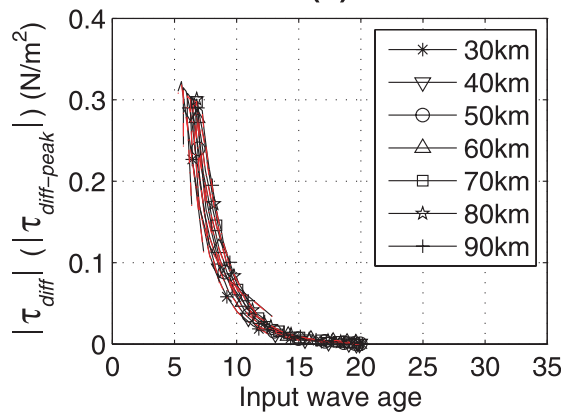

(d)

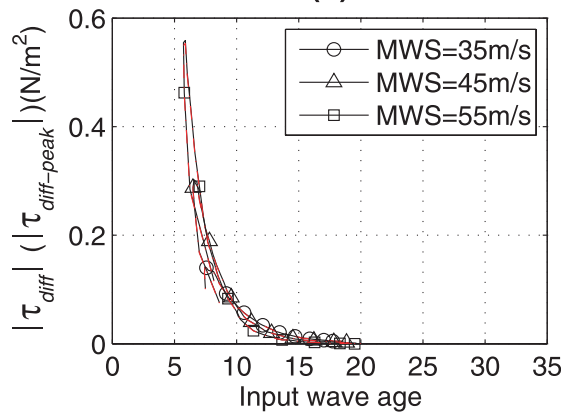

FIG. B2. (a) Net momentum flux gain/loss $\tau_{\text {diff }}$ (black lines) and $\left|\tau_{\text {diff-peak }}\right|$ (red lines) vs (a) normalized distance from the center and (b) input wave age in expt $\mathrm{A}$ and vs (c) normalized distance from the center and (d) input wave age in expt B. Different symbols denote different (a),(b) RMWs and (c),(d) MWSs, as shown in the legend.

where subscripts $\alpha$ and $\beta$ denote unit horizontal coordinates, $S_{\alpha \beta}$ is the radiation stress, $\bar{\tau}_{t \alpha}$ is the momentum transfer by turbulence, $\bar{\tau}_{p \alpha}$ is the momentum transfer by pressure, and $U_{\alpha}=U_{c \alpha}+u_{s \alpha}$ is the sum of the (Eulerian) ocean current $U_{c \alpha}$ and the Stokes drift $u_{s \alpha}$. The surface boundary condition is

$$
\bar{\tau}_{t \alpha}+\bar{\tau}_{p \alpha}=\tau_{\text {air }} \quad \text { at } \quad z=\hat{\eta}
$$

where $\hat{\eta}$ is the mean water elevation. The momentum equation $(\mathrm{C} 1)$ can be rewritten as

$$
\begin{aligned}
\frac{\partial}{\partial t} U_{c \alpha}+\frac{\partial}{\partial x_{\beta}}\left(U_{c \alpha} U_{c \beta}\right)+\frac{\partial}{\partial z}\left(W U_{c \alpha}\right)-\varepsilon_{\alpha \beta z} f U_{c \beta}= & -\frac{1}{\rho} \frac{\partial P}{\partial x_{\alpha}}+\frac{\partial \bar{\tau}_{t \alpha}}{\partial z}+\frac{\partial \bar{\tau}_{p \alpha}}{\partial z}-\frac{\partial}{\partial t} u_{s \alpha}-\frac{\partial}{\partial x_{\beta}} S_{\alpha \beta}+\varepsilon_{\alpha \beta z} f u_{s \beta} \\
& -\frac{\partial}{\partial x_{\beta}}\left(u_{s \alpha} u_{s \beta}\right)-\frac{\partial}{\partial x_{\beta}}\left(U_{c \alpha} u_{s \beta}\right)-\frac{\partial}{\partial x_{\beta}}\left(u_{s \alpha} U_{c \beta}\right)-\frac{\partial}{\partial z}\left(W u_{s \alpha}\right) .
\end{aligned}
$$

Here, the first line is equivalent to the traditional ocean current equations and the second and third lines represent all surface-wave-related terms. If the vertical resolution of the ocean model is coarse, such as typically used in research and operational TC-ocean coupled models, most of the wave effects are applied to a top layer of 5-10-m depth. In addition, all terms in the second line of (C3) are determined by the surface wave field only and are independent of the ocean current velocity. Therefore, we may integrate the second line of (C3) across the wave boundary layer from $z=-\infty$ to $z=\hat{\eta}$ and add the result to the top boundary condition for the first (top) layer momentum equation. In the deep water limit, the resulting equation and boundary conditions for the top layer can be written as

$$
\begin{gathered}
\frac{\partial}{\partial t} U_{c \alpha}+\frac{\partial}{\partial x_{\beta}}\left(U_{c \alpha} U_{c \beta}\right)+\frac{\partial}{\partial z}\left(W U_{c \alpha}\right)-\varepsilon_{\alpha \beta z} f U_{c \beta} \\
=-\frac{1}{\rho} \frac{\partial P}{\partial x_{\alpha}}+\frac{\partial \bar{\tau}_{t \alpha}}{\partial z}-\frac{\partial}{\partial x_{\beta}}\left(u_{s \alpha} u_{s \beta}\right)-\frac{\partial}{\partial x_{\beta}}\left(U_{c \alpha} u_{s \beta}\right) \\
-\frac{\partial}{\partial x_{\beta}}\left(u_{s \alpha} U_{c \beta}\right)-\frac{\partial}{\partial z}\left(W u_{s \alpha}\right),
\end{gathered}
$$


with

$\bar{\tau}_{t \alpha}=\tau_{\text {air }}-\frac{\partial}{\partial t} M_{\alpha}-\frac{\partial}{\partial x_{\beta}} M F_{\alpha \beta}-\tau_{s \alpha} \quad$ at $\quad z=\hat{\eta}$.

Here, the first line is equivalent to the traditional ocean current equations. In the boundary condition (C5), the second and third terms on the right,

$$
-\frac{\partial}{\partial t} M_{\alpha}-\frac{\partial}{\partial x_{\alpha}} M F_{\alpha \beta},
$$

are identical to the air-sea momentum flux budget terms in Eqs. (5) and (6), and the fourth term, $-\tau_{s \alpha}$, is called Coriolis-Stokes forcing term (Polton et al. 2005).

The second line of (C4) includes the advection terms related to the Stokes drift and the interaction term between the Stokes drift and the ocean current vorticity, originally introduced by Craik and Leibovich (1976) and later included in McWilliams and Restrepo (1999) and others. The latter term is known to be critically important for the evolution of Langmuir circulations and Langmuir turbulence.

Let us estimate the magnitude of thee advection terms in (C4) under TC conditions. Both the Eulerian current $U_{c \alpha}$ and the Stokes drift $u_{s \alpha}$ are typically of $O\left(1 \mathrm{~m} \mathrm{~s}^{-1}\right)$. Since the horizontal resolutions of the ocean model and the wave model are both $O(10 \mathrm{~km})$, this sets the horizontal resolvable length scale of both $U_{c \alpha}$ and $u_{s \alpha}$. Then, these advection terms are smaller than the radiation stress term,

$$
-\frac{\partial}{\partial x_{\alpha}} M F_{\alpha \beta},
$$

by a factor $O\left(\left|U_{c \alpha}\right| / C_{g}\right)$, where $C_{g}$ is typically $O\left(10 \mathrm{~m} \mathrm{~s}^{-1}\right)$ for dominant waves. Based on this scaling argument, the advection terms are of secondary importance relative to the air-sea flux budget terms and the Coriolis-Stokes forcing term for typical TC conditions.

In summary, with resolutions of typical ocean models used for TC-ocean interaction modeling, Mellor's (2008) wave current theory is equivalent to solving the traditional ocean current equations with the modified surface boundary condition, where the wind stress is modified by the air-sea flux budget terms

$$
-\frac{\partial}{\partial t} M_{\alpha}-\frac{\partial}{\partial x_{\alpha}} M F_{\alpha \beta}
$$

and the Coriolis-Stokes forcing term $-\tau_{s \alpha}$. In this study we focus on quantifying the air-sea flux budget terms in TC conditions. Quantifying the effect of the CoriolisStokes term will be a topic of our future investigation.

\section{REFERENCES}

Ardhuin, F., A. D. Jenkins, and K. A. Belibassakis, 2008: Comments on "The three-dimensional current and surface wave equations." J. Phys. Oceanogr., 38, 1340-1350.

Bender, M. A., and I. Ginis, 2000: Real-case simulations of hurricaneocean interaction using a high-resolution coupled model: Effects on hurricane intensity. Mon. Wea. Rev., 128, 917-946.

Chao, Y. Y., J. H. G. M. Alves, and H. L. Tolman, 2005: An operational system for predicting hurricane-generated wind waves in the North Atlantic Ocean. Wea. Forecasting, 20, 652-671.

Craik, A. D. D., and S. Leibovich, 1976: A rational model for Langmuir circulations. J. Fluid Mech., 73, 401-426.

Donelan, M. A., M. Shafel, H. Graber, P. Liu, D. Schwab, and S. Venkatesh, 1992: On the growth rate of wind-generated waves. Atmos.-Ocean, 30, 457-478.

Drennan, W. M., M. A. Donelan, E. A. Terray, and K. B. Katsaros, 1996: Oceanic turbulence dissipation measurements in SWADE. J. Phys. Oceanogr., 26, 808-815.

- G. C. Graber, D. Hauser, and C. Quentin, 2003: On the wave age dependence of wind stress over pure wind seas. J. Geophys. Res., 108, 8062, doi:10.1029/2000JC000715.

Fan, Y., I. Ginis, and T. Hara, 2009a: The effect of wind-wavecurrent interaction on air-sea momentum fluxes and ocean response in tropical cyclones. J. Phys. Oceanogr., 39, 10191034.

,,--- W. Wright, and E. Walsh, 2009b: Numerical simulations and observations of the surface wave fields under an extreme tropical cyclone. J. Phys. Oceanogr., 39, $2097-$ 2116.

French, J. R., W. M. Drennan, and J. A. Zhang, 2007: Turbulent fluxes in the hurricane boundary layer. Part I: Momentum flux. J. Atmos. Sci., 64, 1089-1102.

Ginis, I., 2002: Tropical cyclone-ocean interactions. AtmosphereOcean Interactions, W. Perrie, Ed., Advances in Fluid Mechanics Series, Vol. 33, WIT Press, 83-114.

— K. Z. Dikinov, and A. P. Khain, 1989: A three-dimensional model of the atmosphere and the ocean in the zone of a typhoon. Dokl. Akad. Nauk SSSR, 307, 333-337.

Goda, Y., 2003: Revisiting Wilson's formulas for simplified windwave prediction. J. Waterw. Port Coastal Ocean Eng., 129, 93-95.

Hara, T., and S. E. Belcher, 2002: Wind forcing in the equilibrium range of wind-wave spectra. J. Fluid Mech., 470, 223-245.

_, and —_, 2004: Wind profile and drag coefficient over mature ocean surface wave spectra. J. Phys. Oceanogr., 34, 345-358.

Hasselman, K., and Coauthors, 1973: Measurements of wind-wave growth and swell decay during the Joint North Sea Wave Project (JONSWAP). Dtsch. Hydrogr. Z. (Suppl.), 12, 1-95.

Holland, G. J., 1980: An analytic model of the wind and pressure profiles in hurricanes. Mon. Wea. Rev., 108, 1212-1218.

Hwang, P. A., 2006: Duration- and fetch-limited growth functions of wind generated waves parameterized with three different scaling wind velocities. J. Geophys. Res., 34, 2316-2326.

Khain, A. P., and I. Ginis, 1991: The mutual response of a moving tropical cyclone and the ocean. Beitr. Phys. Atmos., 64, 125-141.

Large, W. G., and S. Pond, 1981: Open ocean momentum flux measurements in moderately strong winds. J. Phys. Oceanogr., 11, 639-657.

McWilliams, J. C., and J. M. Restrepo, 1999: The wave-driven ocean circulation. J. Phys. Oceanogr., 29, 2523-2540. 
Mellor, G., 2003: The three-dimensional current and surface wave equations. J. Phys. Oceanogr., 33, 1978-1989.

- , 2005: Some consequences of the three-dimensional currents and surface wave equations. J. Phys. Oceanogr., 35, 22912298.

_- 2008: The depth-dependent current and wave interaction equations: A revision. J. Phys. Oeanogr., 38, 2587-2596.

Moon, I.-J., I. Ginis, T. Hara, H. Tolman, C. W. Wright, and E. J. Walsh, 2003: Numerical simulation of sea-surface directional wave spectra under hurricane wind forcing. J. Phys. Oceanogr., 33, 1680-1706.

,,,--- S. E. Belcher, and H. Tolman, 2004a: Effect of surface waves on air-sea momentum exchange. Part I: Effect of mature and growing seas. J. Atmos. Sci., 61, 2321-2333.

$\longrightarrow, \ldots$, and $\longrightarrow, 2004 \mathrm{~b}$ : Effect of surface waves on air-sea momentum exchange. Part II: Behavior of drag coefficient under tropical cyclones. J. Atmos. Sci., 61, 2334-2348.

,$- \ldots$, and — 2008: Impact of reduced drag coefficient on ocean wave modeling under hurricane conditions. Mon. Wea. Rev., 136, 1217-1223.

Polton, J. A., D. M. Lewis, and S. E. Belcher, 2005: The role of wave-induced Coriolis-Stokes forcing on the wind-driven mixed layer. J. Phys. Oceanogr., 35, 444-457.

Powell, M. D., 2007: Drag coefficient distribution and wind speed dependence in tropical cyclones. NOAA/Joint Hurricane Testbed Program Final Rep., 26 pp.
Tolman, H. L., 1998: Validation of a new global wave forecast system at NCEP. Ocean Wave Measurements and Analysis, B. L. Edge and J. M. Helmsley, Eds., ASCE, 777-786.

_ 2002a: User manual and system documentation of WAVEWATCH-III version 2.22. NOAA/NWS/NCEP/OMB Tech. Note 222, 133 pp.

— 2002b: Validation of WAVEWATCH III version 1.15 for a global domain. NOAA/NWS/NCEP/OMB Tech. Note 213, $33 \mathrm{pp}$.

— , and D. Chalikov, 1996: Source terms in a third-generation wind wave model. J. Phys. Oceanogr., 26, 2497-2518.

__ and J.-H. G. M. Alves, 2005: Numerical modeling of wind waves generated by tropical cyclones using moving grids. Ocean Modell., 9, 305-323.

_, B. Balasubramaniyan, L. D. Burroughs, D. Chalikov, Y. Y. Chao, H. S. Chen, and V. M. Gerald, 2002: Development and implementation of wind generated ocean surface wave models at NCEP. Wea. Forecasting, 17, 311-333.

— J.-H. G. M. Alves, and Y. Y. Chao, 2005: Operational forecasting of wind-generated waves by Hurricane Isabel at NCEP. Wea. Forecasting, 20, 544-557.

Wright, C. W., E. J. Walsh, D. Vandemark, and W. B. Krabill, 2001: Hurricane directional wave spectrum spatial variation in the open ocean. J. Phys. Oceanogr., 31, 2472-2488.

Young, I. R., 2006: Directional spectra of hurricane wind waves. J. Geophys. Res., 111, C08020, doi:10.1029/2006JC003540. 